\title{
TRAS LA PISTA DEL INCA EN PETROGLIFOS PARAVECINALES AL QHAPAQÑAN EN EL ALTO LOA, NORTE DE CHILE
}

\author{
IN THE FOOTSTEPS OF THE INCA THROUGH NEIGHBOURING \\ PETROGLYPHS SITES ALONG THE QHAPAQÑAN IN ALTO LOA, \\ NORTHERN CHILE
}

\author{
José Berenguer R. ${ }^{1}$, Gloria Cabello B. ${ }^{2}$ y Diego Artigas S.C. ${ }^{3}$
}

\begin{abstract}
La duda acerca de si en realidad existió un arte rupestre propiamente incaico ha obsesionado a los investigadores durante décadas. En este artículo se discute este problema con datos del sitio SBa-518, un pequeño asentamiento agropastoril con arte rupestre figurativo tanto naturalista como esquemático, situado a un kilómetro del camino inca del Alto Loa, Región de Antofagasta, norte de Chile. Después de analizar la historia ocupacional del sitio, segregar cinco grupos o subestilos al interior del conjunto esquemático, trazar varias trayectorias de cambio en la figuración de las imágenes y evaluar diferentes escenarios temporales para estos grupos, se confirma que la tradición de camélidos esquemáticos precede en varios siglos a la ocupación incaica en el área. Se propone que tres de estos grupos subestilísticos fueron contemporáneos con el Tawantinsuyu, en particular cuando SBa-518 fue incorporado como asentamiento-satélite a la órbita de los incas.
\end{abstract}

Palabras claves: Andes Centro-Sur, río Loa, caminos incas, Qhapaqñan, arte rupestre, secuencia estilística.

Doubts about whether a truly Inca rock art ever existed have obsessed researchers for decades. This article reflects upon this problem with information gathered from site SBa-518, a small herder-farmer settlement with both naturalistic as well as schematic figurative rock art, located one kilometer from the Inca Road of Alto Loa, in the Antofagasta Region of northern Chile. After analyzing the occupational history of the site, separating five clusters or sub-styles from within the schematic group, tracing several path changes in the image figuration, and evaluating different temporary scenarios for these groups, it is possible to confirm that the schematic camelid tradition precedes the Inca occupation in this area by several centuries. It is proposed that three of these sub-stylistic groups were contemporary with Tawantinsuyu (the Inca Empire), in particular when SBa-518 was incorporated into the Inca orbit as a satellite settlement.

Key words: South-Central Andes, Loa River, Inca roads, Qhapaqnan, rock art, stylistic sequence.

Pese al vasto registro arqueológico dejado por el Tawantinsuyu en algo más de un siglo de expansión, es curioso que hasta ahora no se haya encontrado ningún sitio de arte rupestre figurativo que sea convincentemente atribuible a los incas en todo el imperio. Se han reportado figuras de animales pequeños o simples diseños geométricos grabados en muros de piedra de asentamientos incas, pero éstos son raros y pueden haber sido ejecutados sobre albañilería inca en tiempos coloniales tempranos (Hyslop 1990:11). Pero ¿en realidad existió un arte rupestre figurativo propiamente incaico? Nos referimos a un arte rupestre originado en el Cuzco o sus alrededores, y que durante el Horizonte Tardío haya sido difundido en las provincias por agentes del imperio como parte de una política del Tawantinsuyu. Esta duda ha obsesionado a los estudiosos en los Andes Centro-Sur durante décadas, aunque sólo en los últimos 10 a 15 años ha llegado a ser un tema de preocupación específica entre los investigadores (p.ej. Hernández Llosas 1991, 2006; Gallardo y Vilches 1995; Podestá 1986-87:257; Sepúlveda 2004; Vilches y Uribe 1999; Valenzuela et al. 2004). En este artículo discutimos este problema con datos del valle del Alto Loa, Región de Antofagasta, norte de Chile. Sospechamos que una parte del arte rupestre descrito como "esquemático"

\footnotetext{
Museo Chileno de Arte Precolombino, Casilla 3687, Santiago. jberenguer@museoprecolombino.cl

35 rue Liotard, 1202, Genève, Suisse.glcabello@gmail.com

Universidad Academia de Humanismo Cristiano, Santiago. prestejuan@yahoo.com
} 
en esta área se relaciona de alguna forma con la ocupación inca del Alto Loa. El presente artículo es una evaluación de esta hipótesis de trabajo con información recabada en el sitio SBa-518, donde hay dos amplios conjuntos de grabados: uno naturalista, asignable al Estilo Taira y al período Formativo (Berenguer 1995) y otro esquemático, asignable al Estilo Santa Bárbara I y al período Intermedio Tardío (Berenguer 2004a, 2004b). En este trabajo nos concentramos en este último, con la finalidad de pesquisar posibles subestilos contemporáneos con el Horizonte Tardío.

\section{Antecedentes}

Aunque en la Región de Antofagasta hay cierto acuerdo en la posición cronológica relativa de una decena de estilos de arte rupestre a lo largo de 5.000 años de historia cultural (Berenguer 1999, 2004a; Gallardo et al. 1999), existe un soterrado debate acerca del origen y filiación de dos de los últimos estilos de la secuencia: Santa Bárbara I y Quebrada Seca. Se trata en ambos casos de pequeñas imágenes de camélidos rectilíneos de perfil $(\sim 15-20 \mathrm{~cm}$ de ancho y alto) grabadas y -menos frecuentemente- pintadas, plasmadas en una modalidad esquemática de gran economía de líneas y síntesis formal, si bien carentes de todo dinamismo. Aparecen solas en los paneles, en pares, dispersas o bien en hileras de tres o más animales unidos por una línea, a veces con un bulto en el lomo y precedidos por una figura humana. Estos camélidos esquemáticos son parte de una modalidad muy difundida en los Andes Centro-Sur de representar convencionalmente a la llama (Lama gla$m a)$ y a veces a la llama carguera (Berenguer 2004b:430-434). Los sitios suelen aparecer cerca de asentamientos y zonas de producción agrícola (Gallardo et al. 1999), pero también a la vera de senderos troperos o en aisladas paskanas donde los llameros y sus recuas pernoctaban durante sus expediciones de intercambios. Por eso, mucho de este arte rupestre ha sido interpretado como manifestaciones ceremoniales de antiguos caravaneros (Núñez 1985; Yacobaccio 1979). En unos pocos sitios, las imágenes se asocian a figuras humanas con cascos emplumados, túnicas, petos de cuero, cuchillos, hachas y pieles de jaguar, lo que ha llevado a interpretar estas últimas manifestaciones como discursos relacionados con el poder y la identidad de grupos (Berenguer 2004a).
Algunos atribuyen esta imaginería a tiempos pre Inca (Aschero 1979; Berenguer 2004b; Núñez 1985; Yacobaccio 1979), incluso uno de nosotros retrotrae sus más remotos orígenes y dispersión en la región a pastores y caravaneros de los Andes Centro-Sur que sobrevivieron a la fragmentación de la esfera de Tiwanaku (Berenguer 2004a). Otros sostienen que es de filiación Inca o que sólo aparece en la Región de Antofagasta en contemporaneidad con los incas (Gallardo et al. 1999; Gallardo y Vilches 1995; Núñez 1999; Sepúlveda 2004; Uribe y Carrasco 1999; Varela 1999; Vilches y Uribe 1999). En algunos escritos, inclusive, se reporta esta imaginería en las inmediaciones de un ramal del camino inca que pasa por la cuenca alta del río Salado, asociándolo a la presencia inca y a su sistema vial en la región (Varela 1999:95).

Recientes estudios nuestros en el Qhapaqñan contribuyen, si no a resolver, por lo menos a disipar algunas aristas del problema. Hyslop (1984:339; también Nielsen 1997), por ejemplo, dice que los caminos imperiales que ofrecen mejores perspectivas para la recolección de grandes cantidades de información arqueológica inca son, generalmente, las arterias importantes que pasan por áreas aisladas y desoladas. Allí la conservación arqueológica es excelente y los componentes incas son más evidentes, debido a que las influencias culturales locales son mínimas. De hecho, los mejores hallazgos de arquitectura y cerámica propiamente incas en la región han tenido lugar en el "Despoblado de Atacama" (Hyslop 1984; Niemeyer y Rivera 1983), que es un área virtualmente deshabitada y, por lo tanto, con menos complicaciones interculturales que zonas con ocupaciones locales densas, como el río Salado o la zona de San Pedro de Atacama. Pensamos que, si en realidad hubo un arte rupestre propiamente inca, estas áreas “internodales”, por donde pasa el Qhapaqñan, debieran ser ideales para producir evidencia al respecto.

Una de estas áreas internodales es el Valle del Alto Loa o brazo superior de este río. Aprovechando una prospección de caminos, pedestre y de cobertura total pusimos especial cuidado en examinar cada lugar, hito caminero y asentamiento localizado junto al camino o en su franja inmediatamente aledaña, en busca de sitios de arte rupestre. Desde la localidad de Miño en el norte (536023 E / $7659621 \mathrm{~N}$ / $3932 \mathrm{msm}$ ) hasta la de Lasana en el sur (537950 E / 7537707 N / 2677 msm), nues- 
tra prospección cubrió 125,07 km lineales. Registramos 194 segmentos de camino inca de visibilidad variable (promedio $4 \mathrm{~m}$ de ancho), 13 cuestas con alguna construcción formal, 63 hitos camineros, dos pórticos y 36 asentamientos laterales al camino, 10 de los cuales son de filiación inca (Berenguer et al. 2005). Aunque la cerámica local y la cerámica Inca Local representan lejos el mayor porcentaje de cerámica recolectada a lo largo de la arteria, entre $9 \%$ y $12 \%$ es del tipo Inca Cusco Polícromo, un porcentaje elevado para los estándares de la región. Interesantemente, en nuestra prospección constatamos una total ausencia de arte rupestre, pese a que la vía pasa por numerosas zonas rocosas, varias de ellas óptimas para pintar o grabar imágenes.

Este resultado concuerda con otros antecedentes que se conocen sobre el sistema vial de los incas en los Andes. Hyslop (1984) reporta sólo dos sitios con arte rupestre en 12 trayectos de camino de longitud similar al del Alto Loa, que documentó entre Ecuador y Chile: un petroglifo en la apacheta de Ingañán, en Argentina y otro situado entre los sitios HN y JI, junto al camino inca del "Despoblado de Atacama", en Chile, ninguno de los cuales es asimilable al arte rupestre discutido en este artículo. Más aún, las apachetas son montículos ceremoniales que parecen corresponder a un tiempo ulterior al Horizonte Tardío (A. Nielsen comunicación personal 2004) y el petroglifo del "Despoblado" podría ser más temprano o más tardío que los incas, ya que éstos integraban rutas más antiguas a su red vial y ésta siguió parcialmente en uso con posterioridad al Tawantinsuyu (Berenguer et al. 2005; Hyslop 1984:270 y ss.; Niemeyer y Rivera 1983:155). En otro trayecto prospectado por Hyslop et al. (1992) entre Yanahuanca y Huánuco Pampa, Perú, no reportó ningún sitio de arte rupestre. Podría dudarse, quizás, de que este autor se haya preocupado consistentemente de registrar arte rupestre en su prospección de la vialidad imperial. Sin embargo, de la lectura de su monografía es claro que fue muy minucioso en registrar toda clase de rasgos junto al camino y que los sitios de arte rupestre estaban dentro de sus preocupaciones, por lo que es improbable que los haya pasado por alto (véase Hyslop 1984:162, 180, 271; Hyslop 1976, 1990:11). En suma, desde la perspectiva ofrecida por el trayecto de camino prospectado por nosotros en el Alto Loa y de otros 13 trayectos estudiados por Hyslop (1984; Hyslop et al. 1992) en dife- rentes puntos de los Andes, el arte rupestre no parece haber sido un componente de la vialidad inca. En consecuencia, la controversia acerca de si en realidad hubo un arte rupestre propiamente inca en la región, por lo menos debiera excluir al $Q h a-$ paqñan de la discusión (Berenguer y Cabello 2005). Esta constatación nos llevó a extender la búsqueda a zonas que se hallasen a más distancia del camino, pero que, no obstante, estuvieran físicamente vinculadas con él.

El único asentamiento con arte rupestre que satisfizo esta condición, fue SBa-518, ubicado en las vecindades del Tramo 6 (Bajada del Toro-Cerro Colorado) del Trayecto Miño-Lasana del camino inca del Alto Loa (Berenguer et al. 2005). Su vinculación con el Qhapaqñan consiste en un ramal de esta vía, de un kilómetro de largo, que lo une físicamente con CG-9 (537944 E/7593005 N, $3.271 \mathrm{msm}$ ), un asentamiento con una densa ocupación inca, situado a la vera de la arteria y junto a una antigua paskana caravanera. O sea, SBa-518 no es un sitio lateral, sino "paralateral" o "paravecinal" al eje vial incaico. El ramal o desviación comienza en CG-9 como un camino inca, pero llega a SBa-518 transformado en un sendero tropero, situación no extraña en el sistema vial de los incas, ya que éstos no se molestaban en construir un camino donde un sendero era suficiente (Hyslop 1991:29). Estos antecedentes sugieren que, si hay en el Alto Loa un sitio que puede entregar información acerca del arte rupestre durante el período de actividad inca en el Qhapaqñan, ese es SBa-518.

\section{El Sitio y su Escenario}

La localidad de Bajada del Toro se encuentra en la banda oeste del curso superior del río Loa, a unos $54 \mathrm{~km}$ al norte del Pukara de Lasana, $8 \mathrm{~km}$ al norte del sitio incaico de Cerro Colorado-1 y $9 \mathrm{~km}$ al sur del sitio multicomponente con ocupación inca de Lequena Viejo (Berenguer et al. 2005). Se sitúa junto a la moderna Ruta B-141, en la desértica Pampa Chela Cruz, entre las quebradas Seca y Las Cruces, casi frente a la Quebrada Macho Muerto (Figura 1).

\section{El sitio}

El sitio SBa-518 no está exactamente en Pampa Chela Cruz, sino en el interior del cañón del 


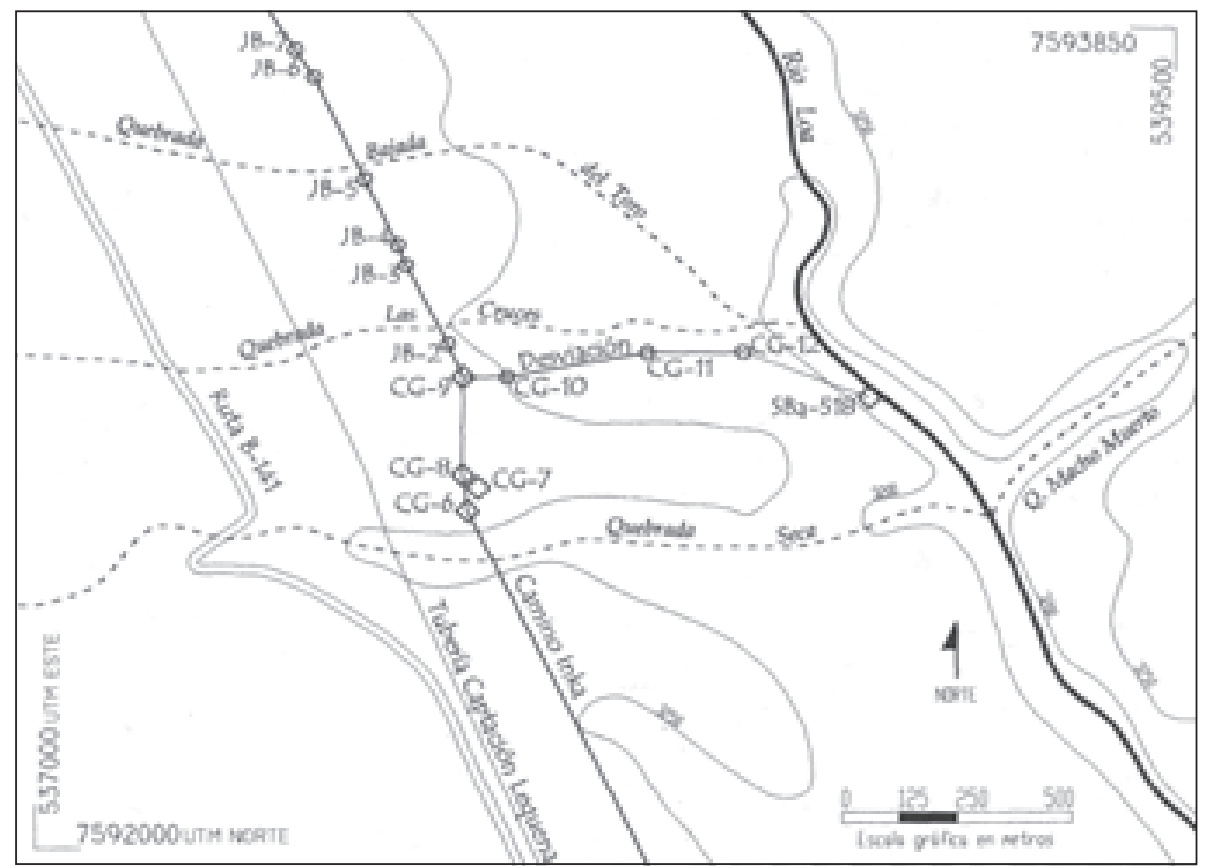

Figura 1. Mapa de situación de los sitios y puntos mencionados en el texto. Localidad Bajada del Toro, Alto Loa. Map of the sites and areas mentioned in the text. Bajada del Toro locality, Alto Loa.

Loa, que aquí tiene unos $50 \mathrm{~m}$ de alto y $150 \mathrm{~m}$ de ancho (Figura 2) y está formado por flujos piroclásticos soldados: arriba, ignimbritas dacíticas; abajo, ignimbritas riolíticas. El piso del valle tiene una anchura aproximada de $80 \mathrm{~m}$, sobre el cual serpentea el río Loa, flanqueado por una cubierta de grama salada y una cinta de colas de zorro bastante densa en las orillas.

El conglomerado habitacional cubre 9.150 $\mathrm{m}^{2}$. Consta de 83 estructuras de piedras (E- $n$ ), una parte de las cuales son recintos de forma irregular, aunque también los hay de planta semicircular, circular y subrectangular (Figura 3). El resto son alineamientos de piedras que no conforman recintos. El centro del asentamiento se extiende sobre derrubios, en ocasiones sobre roca desnuda y, en los extremos norte y sur del sitio, sobre grandes escombros de falda. Lo hace desde la pared del cañón, situada a unos $35 \mathrm{~m}$ de altura, hasta la terraza del Loa. En superficie presenta abundante cerámica, lítica tallada y lítica pulida, incluyendo morteros planos y rectangulares, como también gran cantidad de manos de moler planas y oblongas.

Con fines operativos, dividimos el sitio en un eje longitudinal, que atraviesa por la parte media del talud en dirección aproximadamente norte-sur y otro transversal que cruza desde la pared del cañón hasta el piso del valle. En los cuadrantes SW y NW se halla el "sector alto" del asentamiento, formado por 48 estructuras, dispersas en el primer cuadrante y relativamente aglutinadas en el segundo; sobre el eje longitudinal y sus franjas inmediatamente aledañas está el "sector medio", carente de estructuras; y en los cuadrantes SE y NE se encuentra el "sector bajo" del asentamiento, formado por 35 estructuras, dispersas en el primer cuadrante y relativamente aglutinadas en el segundo. Los cuadrantes con mayor densidad de estructuras son el NW y el NE. Coinciden con una acentuada inflexión de la pared del cañón y con una depresión del talud, donde hay mayor número de superficies terraceadas para pisos de habitación y bloques rocosos de gran volumen para cerrar los recintos con menor inversión de trabajo. Esta depresión protege del viento, ya que inmediatamente al norte y sur hay derrumbes más altos y abruptos, dejando entremedio un área notoriamente más abrigada.

Si bien el área con mayor actividad ocupacional se halla en los cuadrantes NE y NW, el "núcleo del asentamiento" parece haber estado en este últi- 


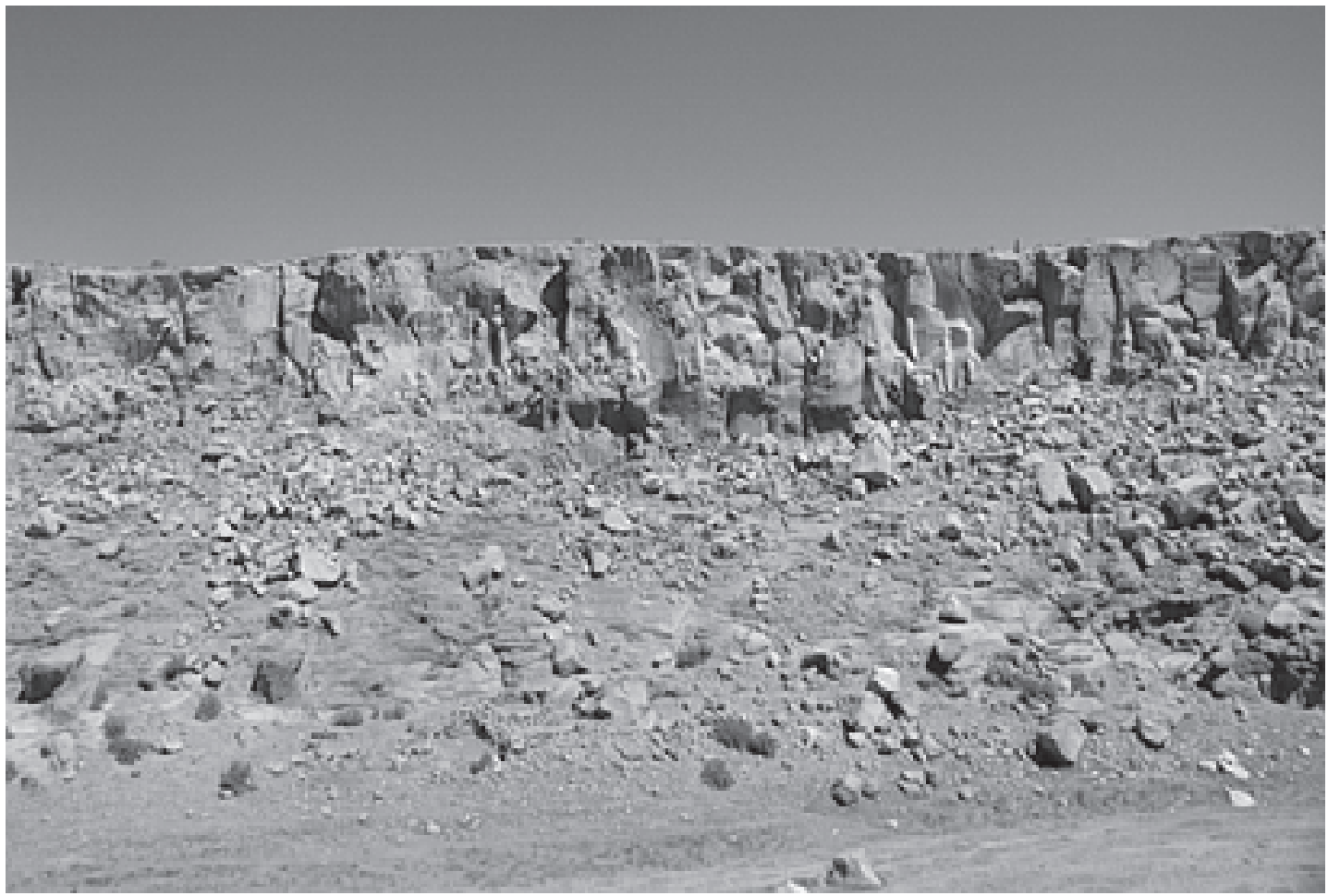

Figura 2. Panorámica del sector central del sitio SBa-518 desde el oriente.

Panoramic view of site SBa-518's central sector as seen from the east.

mo cuadrante. Aparte de su mayor cantidad de estructuras ( $60 \%$ del total), allí están los abrigos rocosos, incluyendo algunas bodegas (E-9 y -20A). Allí, igualmente, se encuentran las dos únicas estructuras con muros de doble hilera de piedras (E-9 y -20). Alineados de norte a sur, entre las cotas de 25 y $30 \mathrm{~m}$, este cuadrante contiene, además, cinco bloques sueltos con cúpulas ovales (hay un sexto bloque en el cuadrante SW), como también una "tacita" cilíndrica y surcos ondulantes originados en pequeñas cúpulas rectangulares. Asimismo, este cuadrante presenta una suerte de "patio" de $20 \mathrm{~m}$ de ancho por $10 \mathrm{~m}$ de fondo, rodeado por más de una docena de recintos. Por último, en este cuadrante están 106 de los 120 paneles (P-n) de arte rupestre del sitio ( $\sim 88 \%$ del total), principalmente en la pared del cañón y en bloques sueltos, con unos pocos plasmados en muros de recintos. Claramente, entonces, el conjunto arquitectónico del cuadrante NW es el más complejo de todo el sitio y puede considerarse con propiedad el "núcleo" de SBa-518.

\section{Historia Ocupacional de SBa-518}

Diez dataciones por TL y $\mathrm{C}^{14}$ (Tabla 1) muestran que el sitio SBa-518 fue ocupado desde el período Intermedio Tardío hasta tiempos Postcontacto, incluyendo el lapso aceptado hoy en día para la ocupación inca en la región (ca. 1.400-1.535 d.C.).

La cerámica, en cambio, retrotrae el comienzo de la ocupación a tiempos pre Intermedio Tardío, pero en general es coherente con la cronología radiométrica (Uribe y Cabello 2005). Se recuperaron 1.330 fragmentos, 743 de la superficie y 587 de excavaciones en el interior de los recintos $(55,86 \%$ y $44,14 \%$ del total, respectivamente). Un $81 \%$ son tipos cerámicos identificables: Loa Café Alisado (LCA, $\mathrm{n}=1-2$ ); Ayquina (AYQ, $\mathrm{n}=238$ ), Dupont (DUP, $\mathrm{n}=90$ ), San Pedro Rojo Violáceo (SRV, $\mathrm{n}=2-4)$, Turi Gris Alisado (TGA, $\mathrm{n}=224$ ), Turi Rojo Alisado (TRA, $\mathrm{n}=423$ ), Turi Rojo Burdo (TRB, $n=3$ ), Turi Rojo Revestido Pulido (TRP, n=19) y Turi Rojo Revestido (TRR, n=37), así como Hedionda (ED, $n=2)$ y Pica Charcollo (PCH, n=2); Turi Rojo Revestido Pulido Ambas 


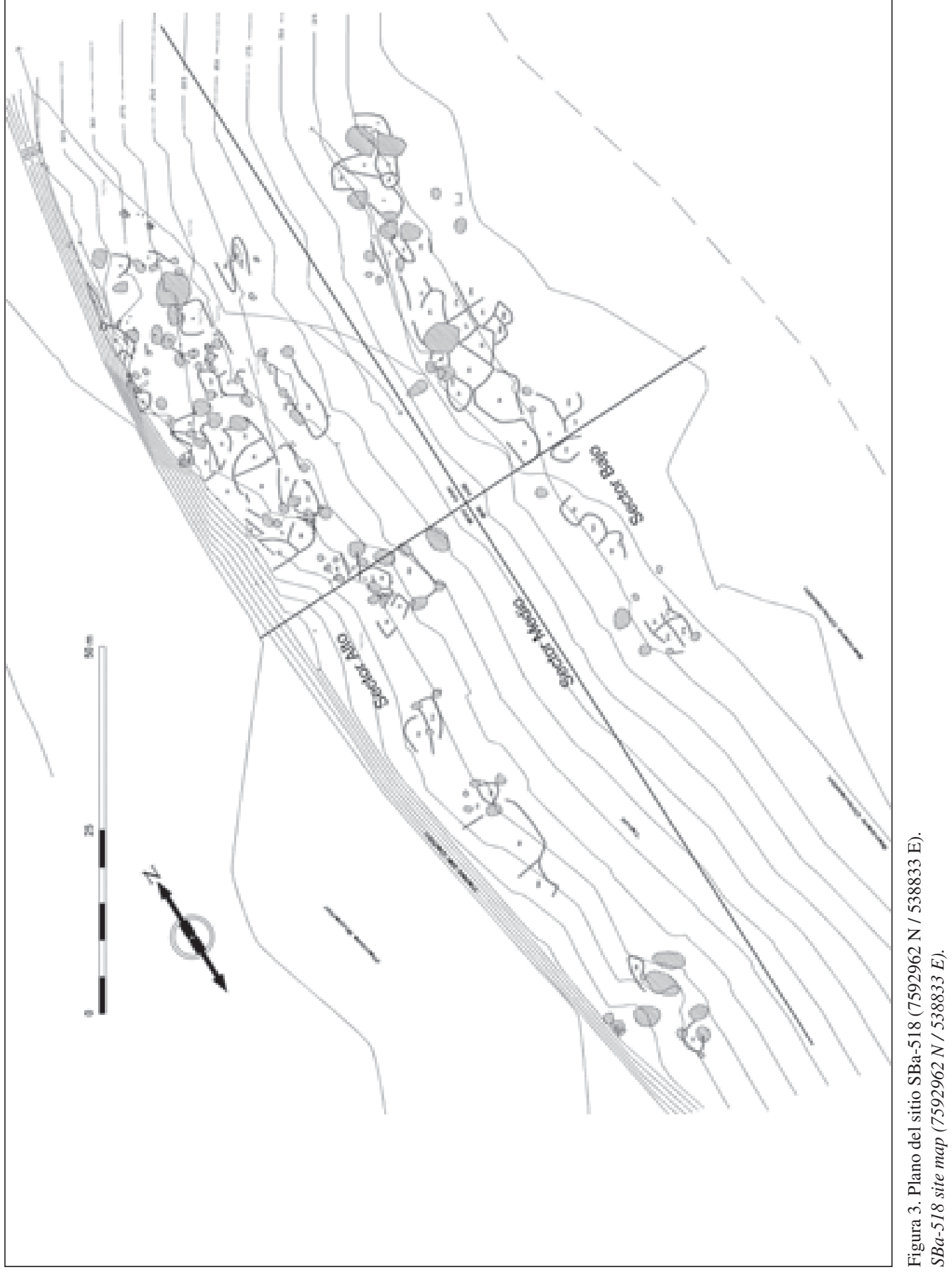


Caras ( $\mathrm{n}=1)$ y Turi Rojo Revestido Exterior-Negro Alisado Interior $(\mathrm{n}=1)$, además de Lasana Caférojizo Revestido (LCR, $n=1$ ) y Lasana Café-rojizo Revestido Pulido Interior LCP, $n=1$ ), junto con Diaguita Incaico (DIA, n=1) y Yavi-La Paya (YAV, $\mathrm{n}=1)$; y, por último, los tipos Santa Bárbara Rojo Burdo (SBR, n=21) y Turi Café Alisado (TCA, $\mathrm{n}=11-16)$. Estas cerámicas muestran a $\mathrm{SBa}-518$ como un sitio multicomponente, que abarca los períodos Formativo, Intermedio Tardío, Horizonte Tardío y Postcontacto.

\section{Período Formativo}

La mínima presencia de fragmentos LCA, concentrados en E-30 ( $0,15 \%$ del total), impide realizar inferencias sólidas acerca de este episodio de ocupación. Seguramente fueron dejados por utilizaciones pasajeras del sitio, quizás por poblaciones que ocupaban el lugar de manera esporádica y dispersa. Los fragmentos fueron encontrados en los niveles más profundos de las excavaciones, cuestión que corrobora su mayor antigüedad. Con todo, no se encontraron pruebas de que algún recinto visible en el sitio haya sido construido durante esta temprana ocupación.

\section{Período Intermedio Tardío}

La cerámica de este período, en cambio, es abrumadoramente predominante en el sitio $(78,35 \%)$. Una gran proporción proviene de la excavación de sólo seis estructuras, evidenciando la existencia de densos depósitos; el resto procede de la superficie de otras 15 estructuras. Esta predominancia es también consistente con la alta frecuen- cia alcanzada por las escudillas DUP y AYQ $(6,77$ y $17,89 \%$, respectivamente), sin olvidar la presencia del diagnóstico tipo SRV. Por lo tanto, al revisar cada una de las estructuras estudiadas y sus depósitos, se infiere una ocupación y utilización secuencial del espacio por grupos independientes, aunque agregados y complementarios en el tiempo. Más que un conjunto diferenciado de espacios $\mathrm{y}$ funciones bien articuladas dentro del asentamiento, se observan eventos separados, en los que se emplean las mismas construcciones, pero de múltiples maneras, si bien con marcado énfasis doméstico. Visualizamos el desarrollo del sitio como parte de un patrón de asentamiento característico del Alto Loa, conformado por asentamientos agropastoriles que nunca alcanzaron las dimensiones y complejidad de los grandes poblados del Alto Salado y de la cuenca del salar de Atacama, aunque podrían compararse con sus exponentes más pequeños (Berenguer 2004b:333-368). SBa-518 sería un caserío grande o villorrio, dotado de una cantidad de recintos algo mayor a la usual para estos conglomerados en el valle, situación que podría deberse a una más larga y compleja historia ocupacional respecto de sus equivalentes locales.

La ocupación de SBa-518 es de carácter esencialmente doméstico o familiar, no obstante, se insinúan actividades de carácter más colectivo o comunitario, probablemente relacionadas con eventos festivos y/o rituales. En primer lugar, E-9, -14, $21,-24,-25,-26,-28,-30,-38$ y -40 son recintos habitacionales multifuncionales, característicos del Intermedio Tardío regional, donde los fragmentos de grandes contenedores, platos y ollas locales (TRA, TRB, AIQ, DUP y TGA), así como de fragmentos de vasijas más especiales revestidas rojas

Tabla 1. Dataciones TL y $\mathrm{C}^{14}$ de SBa-518.

TL and C14 dates from SBa-518.

\begin{tabular}{|c|c|c|c|c|c|c|c|}
\hline Código & Proveniencia & Muestra & años d.C. & sigma & - sigma & centro & + sigma \\
\hline 1. UCTL 1582 & SBa-518 C1 C1 & TRP & 1.390 & 60 & 1.330 & 1.390 & 1.450 \\
\hline 2. UCTL 1583 & SBa-518 C1 C1 & TRP & 1.545 & 45 & 1.500 & 1.545 & 1.590 \\
\hline 3. UCTL 1584 & SBa-518 C1 C3 & TRN & 1.640 & 30 & 1.610 & 1.640 & 1.670 \\
\hline 4. UCTL 1585 & SBa-518 C1 C4 & TRP & 1.565 & 40 & 1.525 & 1.565 & 1.605 \\
\hline 5. & SBa-518 E25 C1 C4 & TRP & 1.565 & 40 & 1.525 & 1.565 & 1.605 \\
\hline 6. & SBa-518 E9 Rec.Sup & TCA mica & 1.595 & 40 & 1.555 & 1.595 & 1.635 \\
\hline 7. UCTL 1581 & SBa-518 E-9 Sup & TCA mica & 1.645 & 30 & 1.615 & 1.645 & 1.675 \\
\hline 8. Beta 189483 & SBa-518 E-25/P1/4 & Carbón & 1.400 & 60 & 1.290 & 1.400 & 1.440 \\
\hline 9. Beta 189484 & SBa-518 E-38/1/1R2 & Carbón & 1.180 & 60 & 1.020 & 1.180 & 1.270 \\
\hline 10. Beta 189482 & SBa-518 E-9/1/2 & Carbón & 1.230 & 50 & 1.060 & 1.230 & 1.280 \\
\hline
\end{tabular}


(SRV, TRP y TRR), indican un funcionamiento relacionado con diversas actividades domésticas (p.ej. preparación, consumo y almacenaje de alimentos), pero también con situaciones ceremoniales. En particular, E-25, -26 y -38, con sus contextos relativos a preparación de alimentos, constituirían un área importante de las labores domésticas. Más aún, el centro de este tipo de actividad se ubicaría en E-24, -25 y -26. Complementando esta dinámica, se podrían incluir E-6, -10B, $-34,-48$ y -54 , que exhiben poquísimos fragmentos (escasos a nulos), sumamente pequeños y erosionados, sugiriendo ocupaciones muy livianas y actividades pasajeras o sin mayor uso de cerámicas. Esto último podría deberse a que fueron espacios con funcionalidades diferentes y más especializadas (p.ej. bodegas, corrales, dormitorios, etc.). Así lo insinúan construcciones anexas a las habitacionales (E-10B y -48), que parecen haber estado destinadas a almacenaje. En segundo lugar, el "patio" del núcleo del asentamiento presenta todas las características de un área de uso comunitario, incluyendo actividad ceremonial: se halla rodeada por 14 recintos, incluye tres de las seis piedras con cúpulas y tacitas del sitio, $\mathrm{y}$-como veremos al final de este artículo- se encuentra adyacente al sector con mayor cantidad y variedad de arte rupestre tardío.

Consistente con la estabilidad alcanzada por la ocupación durante el período Intermedio Tardío, algunos recintos (E-21, -24 y -30) comienzan a constituirse en basurales. Una relativa abundancia de material cerámico, su gran variedad tipológica y de clases funcionales, la leve presencia de restauración de vasijas, algunas señas de uso, el pequeño pero irregular tamaño de los fragmentos (seguramente producto del pisoteo diferencial) y la presencia de material erosionado, dan cuenta de contextos que cambian de depósitos "primarios" a "secundarios". Es decir, serían desechos dejados en un primer momento por la ocupación residencial de las estructuras, pero luego, por acumulación atribuible a abandono o, al menos, a un cese de funciones residenciales. Este es particularmente el caso de E-24, que se convertiría en uno de los principales basurales del asentamiento, presentando incluso unos pocos fragmentos incaicos. Tal proceso es consistente con la gran densidad de basuras en E-24, -25 y -26, que indican un incremento de las labores domésticas. O sea, la dinámica ocupacional del sitio se hace más intensa hacia fi- nales del período prehispánico. Como probables elementos generativos de esta situación estarían la intensificación del tráfico caravanero preincaico después de 1.300 d.C. en el valle (Berenguer 2004b:499 y ss.) y el posterior impacto de la actividad inca a través del Qhapaqñan (Berenguer et al. 2005). Después de todo, hay una paskana del Intermedio Tardío y un establecimiento incaico en CG-9, a un kilómetro de distancia de SBa-518, como también una vía de comunicación entre ambos lugares bajo la forma de un sendero tropero que entronca con un ramal del camino inca.

Las excavaciones de E-9 y -30 indican ocupaciones previas a 1.300 d.C. (Fase Quinchamale I). Esta inferencia se basa, por una parte, en la presencia asociada y mayoritaria de los tipos DUP y SRV, frente a la correspondiente escasez de fragmentos AYQ; por otra, se sustenta en la introducción en los niveles medio e inferior de los depósitos de cerámicas foráneas que son tempranas dentro del período, como PCH. En E-30 esta secuencia continúa con otra ocupación clásica del período Intermedio Tardío. En cambio, el recinto E-25 exhibe una ocupación exclusivamente posterior a 1.300 d.C., por su énfasis en los fragmentos AYQ (Fase Quinchamale II), sugiriendo un crecimiento del asentamiento desde el núcleo, en el sector alto, hacia el sector bajo. Mientras las fechas 9 y 10 datarían la primera fase de este proceso ocupacional, la fecha 1 haría lo propio con la segunda fase (Tabla 1).

En síntesis: si obviamos la efímera o elusiva intrusión formativa, la ocupación más efectiva de SBa-518 comenzaría en los inicios del Intermedio Tardío, pero recién promediando el período el sitio pasaría a constituirse en un asentamiento estable y de cierta complejidad. Sus basurales se habrían producido principalmente debido a cambios en la utilización de ciertas estructuras previamente usadas como residencia, proceso que se relacionaría con un crecimiento del asentamiento después de 1.300 d.C., que supuso modificaciones en la funcionalidad de muchas construcciones.

\section{Horizonte Tardío}

La cerámica incaica o directamente relacionable con este período representa apenas el 0,68\% de la muestra. Son tan sólo nueve fragmentos: siete clasificables como Inca Local, uno como Diaguita Incaico y otro como Yavi-La Paya. Si bien dos de ellos (LCP y YAV) proceden de estructuras 
de bodegaje del sector alto del asentamiento (E-9 y -20A), los restantes (DIA, LCE, TRA y TRN) están en recintos y basurales del sector bajo, al pie del talud, casi sobre la terraza del Loa (E-24, -25 y -26). Las fechas 8 y 3 , reflejarían este episodio del Horizonte Tardío, cuya expresión local es conocida como Fase Sirawi (Tabla 1). Hay pocas dudas de que los citados fragmentos arribaron a SBa-518 desde el establecimiento incaico CG-9. De hecho, en los dos sitios se han encontrado fragmentos de la diagnóstica cerámica DIA del norte semiárido de Chile (Uribe y Cabello 2004). Casi podría darse por sentado que todas estas cerámicas fueron transportadas al lugar a través de la desviación del camino inca que vincula físicamente a CG-9 con SBa-518. Por lo demás, las fechas de ambos sitios cubren un rango que incluye al Horizonte Tardío.

\section{Período Postcontacto}

La cerámica Postcontacto alcanza un 2,78\% de la muestra, constituyendo la segunda "más importante" en el sitio desde el punto de vista cuantitativo.

Esta alfarería (SRB y TCA) se encuentra en varios de los mismos conjuntos residenciales ocupados desde el Intermedio Tardío en adelante (p.ej. E-9, -14, -21, -24, -30, -34 y -38), indicando cierta continuidad en la ocupación del lugar, aunque con mucho menor intensidad que en el período previo. En general, esta ocupación tuvo lugar tanto adentro como afuera del núcleo del asentamiento. Las fechas 6,7 y 8 (Tabla 1) parecen datar bien este episodio hispano-indígena y coinciden con las ocupaciones Postcontacto del citado sitio CG-9.

Recapitulando: la secuencia de SBa-518 comprende los siguientes períodos: Formativo Tardío, Intermedio Tardío (fases Quinchamale I y II), Horizonte Tardío (Fase Sirawi) y Postcontacto o Hispano-Indígena. Con estos antecedentes contextuales ahora es posible concentrarse en el estudio del arte rupestre de Estilo Santa Bárbara I en el sitio.

\section{Variabilidad y Dinámica Intraestilística en Santa Bárbara I}

Antes de tratar el Estilo Santa Bárbara I en sus particularidades, permítasenos entregar algunas cifras sobre la totalidad del arte rupestre del sitio (Berenguer et al. 2004). De los 120 paneles del sitio SBa-518, 92 corresponden a caras de 75 bloques sueltos y dispersos a través del sitio, en tanto que 28 son paneles fijos situados en la pared oeste del cañón. Las figuras individuales totalizan 785 . Las de Referentes 0 (motivos indeterminables) y 1 (motivos insuficientemente determinables) totalizan en conjunto un $\sim 40 \%$ del universo, correspondiendo el saldo a las de Referente 2 (motivos plenamente determinables). Las frecuencias de técnicas de ejecución son las siguientes: piqueteado $60 \%(\mathrm{n}=450)$, raspado areal y lineal 33\% $(\mathrm{n}=275)$, inciso $5 \%$ $(\mathrm{n}=36)$, pintura roja areal y lineal $3 \%(\mathrm{n}=16)$ y horadación 2\% ( $\mathrm{n}=12)$. De las 487 figuras de Referente 2 , el $97 \%$ son figuras de camélidos, $2 \%$ de antropomorfos y $1 \%$ de zoomorfos. De los camélidos de Referente 2, el 58\% corresponden a naturalistas, principalmente de Estilo Taira y el $42 \%$ restante a esquemáticos de Estilo Santa Bárbara I. Las frecuencias por técnica de ejecución en estos conjuntos, es como sigue: en los naturalistas, el piqueteado alcanza un $52 \%$, el raspado un $44 \%$ y el inciso un $4 \%$; en tanto que en los esquemáticos, el piqueteado representa el $86 \%$, el raspado el $13 \%$ y el inciso el $1 \%$.

En primer lugar, advertimos que dentro del Referente 2, la imagen del camélido -sea ésta naturalista o esquemática- es completamente dominante $(97 \%)$. Esta constatación aconseja que, para efectos estrictamente prácticos de esta investigación, el análisis del arte rupestre de SBa-518 parta de (y se enfoque en) la variabilidad representacional de este animal, exclusivamente. En segundo lugar, notamos que, pese a que los camélidos naturalistas priman sobre los esquemáticos en una proporción de 4:3, ambos se hallan en cantidades más o menos similares en el sitio. Esta constatación indica que el esquemático Estilo Santa Bárbara I no aparece en SBa-518 como una rareza o una breve intrusión, sino como un arte rupestre cuantitativamente importante en el sitio. En tercer lugar, vemos que si bien la suma de figuras hechas por piqueteado y raspado alcanza el $93 \%$ de los motivos del sitio, ambas técnicas tienen frecuencias similares en los naturalistas, en cambio el piqueteado es lejos la técnica más frecuente en los esquemáticos. Esto significa que, en términos de tecnología rupestre, los camélidos esquemáticos de Estilo Santa Bárbara I establecen -más allá de las evidentes diferencias en las formas de construcción de la imagen del animal- un quiebre en los procedimientos de ejecución respecto de aquellos empleados en el más antiguo Estilo Taira. 


\section{Variabilidad intraestilística}

Ya habíamos adelantado en otra parte nuestra impresión de que el concepto de "Estilo Santa Bárbara I" encubre una considerable variación intraestilística, imponiéndose la necesidad de formalizar subestilos (Berenguer 2004a:104-105). También habíamos anticipado que era preciso hacer nuevas distinciones, con un número de variables o atributos tal, que capturase las diferencias que puedan haber al interior de este Estilo (Berenguer 2004b:427). De otro modo, se perpetúan presunciones normativas sobre su homogeneidad interna, que impiden discernir variaciones potencialmente útiles para responder preguntas como las de esta investigación. En el caso de los camélidos esquemáticos del sitio SBa-518, es indispensable descubrir distinciones que no sólo pongan de manifiesto esta variabilidad, sino también que revelen su dinámica intraestilística, a objeto de identificar -digámoslo así- grupos "alfa" y grupos "secundarios". La expectativa es que el comportamiento cuantitativo de los grupos resultantes y sus líneas de variación en ciertos atributos posibiliten trazar -como objetivo táctico- "trayectorias de cambios" a partir de uno o más grupos "originales" dentro de los períodos considerados. El objetivo estratégico o de más largo alcance de este procedimiento es identificar uno o más subestilos que puedan ser razonablemente asignados al Horizonte Tardío, cuestión que evaluaremos al final del trabajo.

El conjunto de arte rupestre esquemático y de Referente 2 del sitio SBa-518 totaliza 185 figuras individuales de camélidos, todas del Estilo Santa Bárbara I. Basados en atributos de variación, tales como forma de las orejas, número de extremidades, presencia o ausencia de patas, presencia o ausencia de bulto pectoral y otras protuberancias, ejecución areal o ejecución lineal, y oblicuidad u ortogonalidad de los principales elementos de diseño de las figuras es posible distinguir cinco grupos subestilos en este conjunto: A, B, C, D y E. La Figura 4 muestra la frecuencia relativa de estos grupos en el referido universo de 185 figuras individuales. Procedemos enseguida a definirlos en sus características más distintivas.

\section{Grupo A ( $n=149$ figuras, $f=81 \%)$}

Camélidos con dos extremidades, dirigidos hacia la izquierda o derecha del observador, oreja

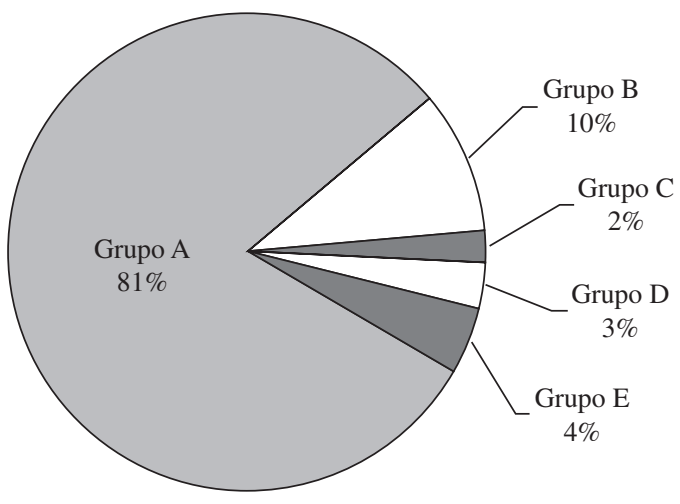

Figura 4. Frecuencia de los grupos A, B, C, D y E. Frequency of Groups $A, B, C, D$ and $E$.

mayoritariamente doblada hacia delante y minoritariamente vertical, cuello mayoritariamente oblicuo y minoritariamente vertical, cuerpo angosto, cola mayoritariamente doblada hacia abajo y minoritariamente recta dirigida hacia arriba o hacia atrás, extremidades verticales u oblicuas y sin figuración de patas (Figura 5).

Grupo B ( $n=18$ figuras, $f=10 \%)$

Camélidos de factura areal, con cuatro extremidades, dirigidos hacia la izquierda o derecha del observador, oreja mayoritariamente única y doblada hacia delante y minoritariamente doble y vertical o en "V", cuello mayoritariamente oblicuo y muy minoritariamente vertical, cuerpo ancho o grueso, cola mayoritariamente doblada hacia abajo y minoritariamente recta dirigida hacia atrás, extremidades verticales u oblicuas y con una muy minoritaria figuración de patas (Figura 6).

Grupo $C$ ( $n=4$ figuras, $f=2 \%$ )

Camélidos con cuatro extremidades, dirigidos hacia la derecha del observador, oreja doblada hacia delante, cuello oblicuo, cuerpo angosto, cola doblada hacia abajo o recta dirigida hacia atrás, extremidades verticales u oblicuas, tendencia a la ortogonalidad en la unión de los elementos de su diseño, figuración de patas y de protuberancias en el pecho, vientre y parte trasera de algunas extremidades (Figura 7). 


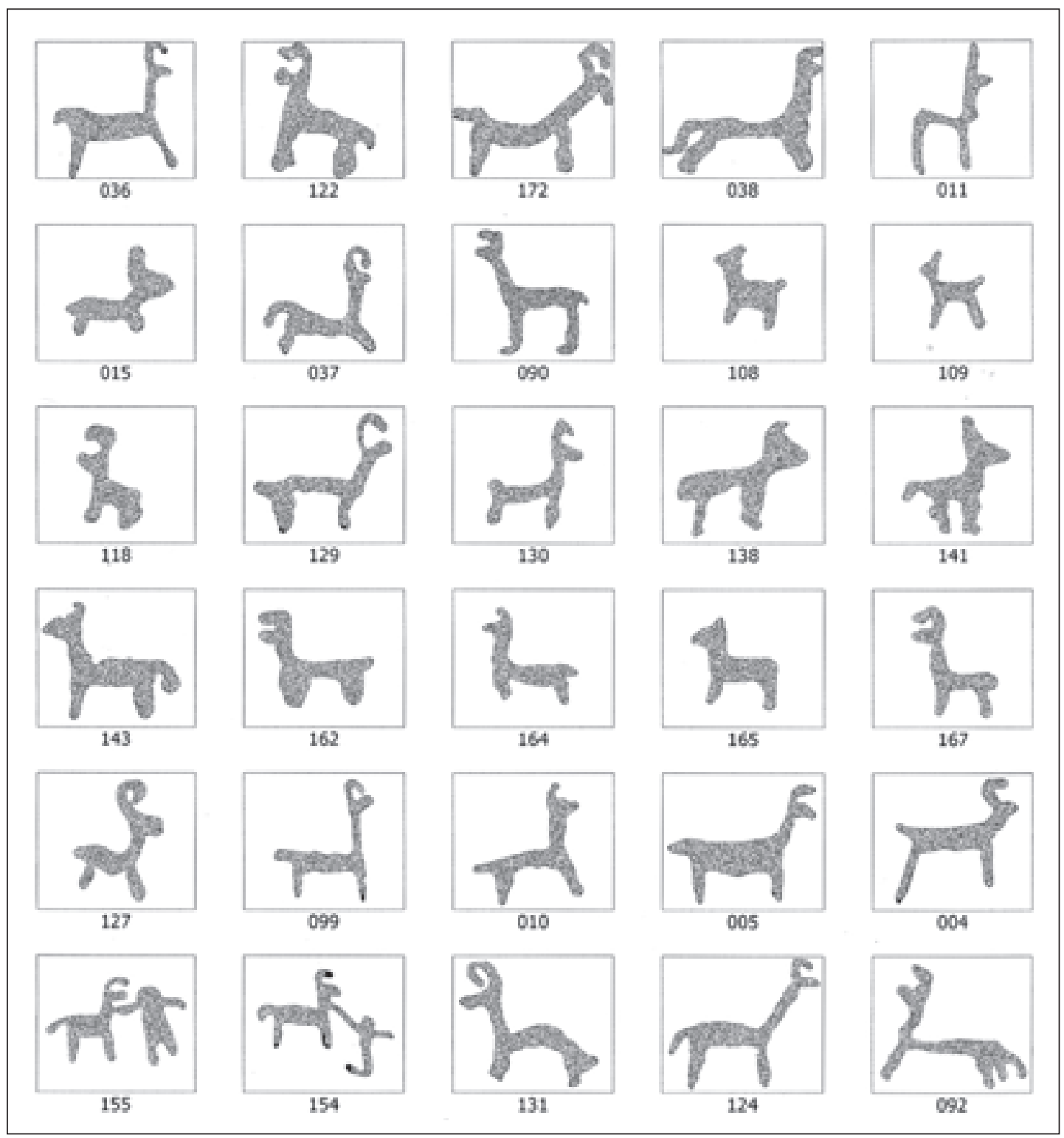

Figura 5. Camélidos del Grupo A.

Camelids of Group A.

\section{Grupo $D(n=6$ figuras, $f=3 \%)$}

Camélidos hiperrectilíneos, con marcada tendencia a la ortogonalidad en la unión de los elementos de su diseño, dirigidos a la izquierda del observador, subdividibles en dos subgrupos. En D1 los camélidos tienen dos extremidades, oreja ligeramente doblada hacia delante, cuerpo, cuello y extremidades lineales, con estas últimas mayoritariamente verticales y sin figuración de patas. En D2 tienen cuatro extremidades, sin figuración de orejas y en dos casos sin figuración de cabeza, cuerpo, cuello y extremidades lineales, cola recta hacia atrás y sin figuración de patas (Figura 8).

\section{Grupo $E(n=8$ figuras, $f=4 \%)$}

Camélidos con cuatro extremidades, dirigidos hacia la izquierda o derecha del observador, oreja ausente, hacia arriba o en "V", cuello oblicuo, cuer- 


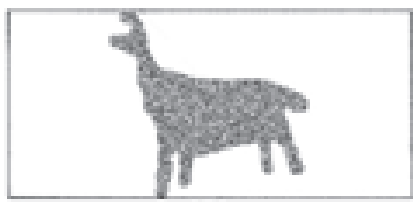

101

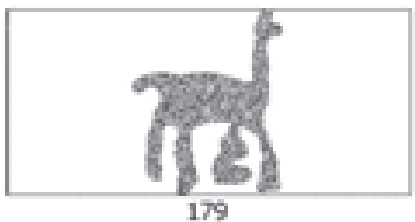

179

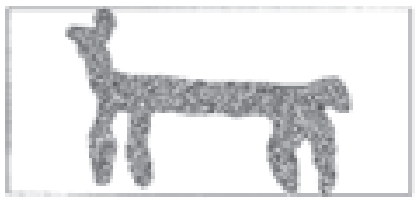

029
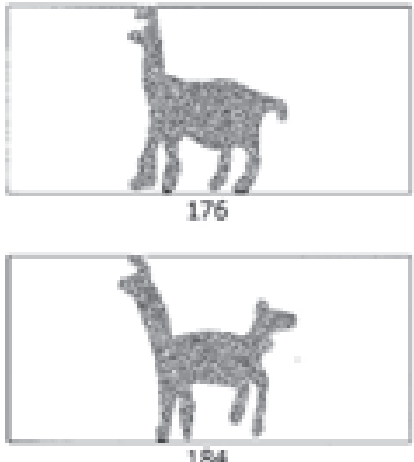

184

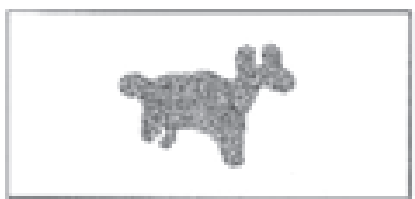

145

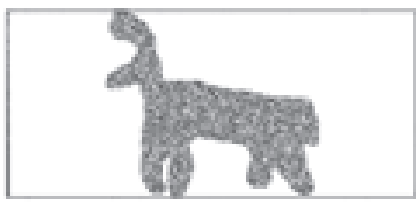

103

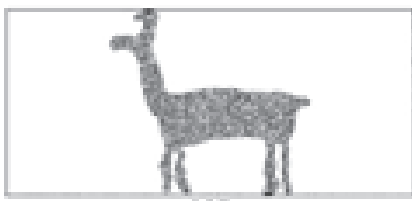

$\infty 07$

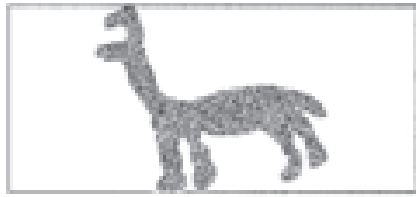

136
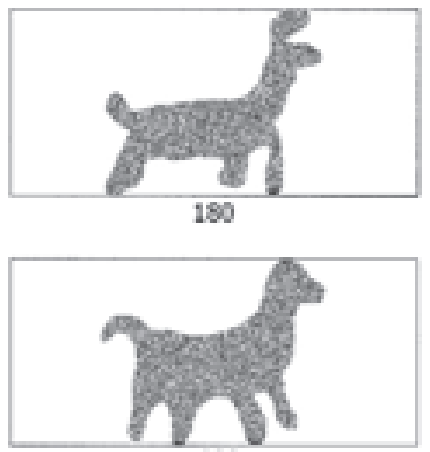

032

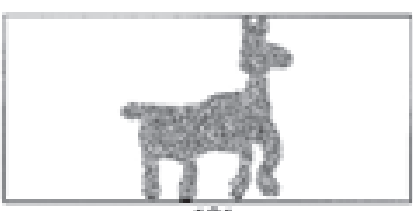

18

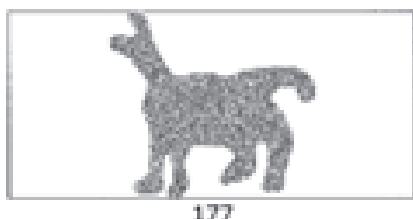

177

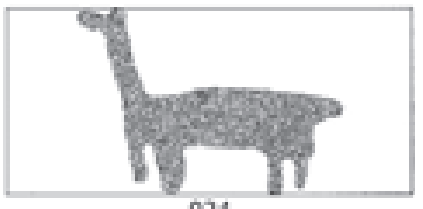

024
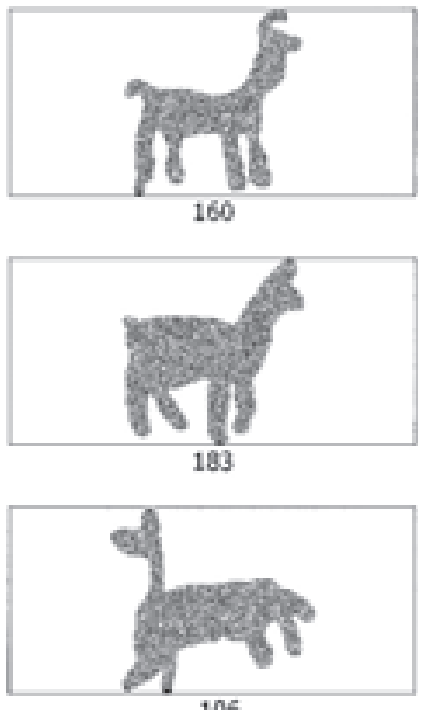

106

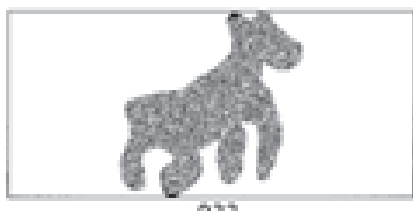

033

Figura 6. Camélidos del Grupo B.

Camelids of Group B.

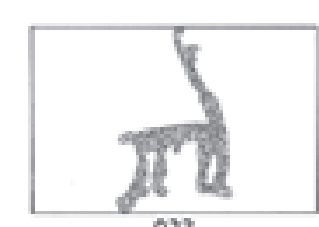

023

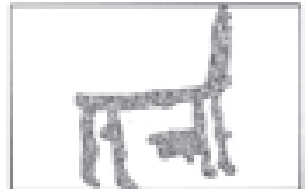

025

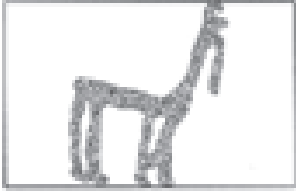

028

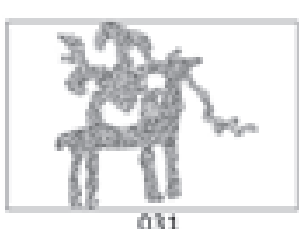

031

Figura 7. Camélidos del Grupo C.

Camelids of Group C. 


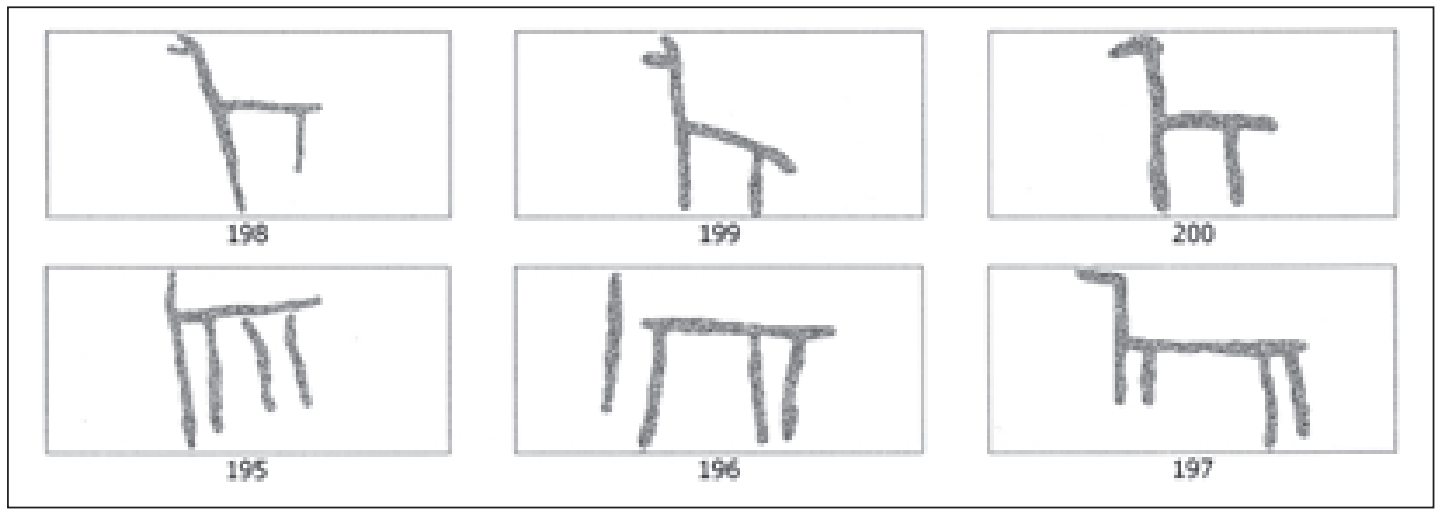

Figura 8. Camélidos del Grupo D. Arriba: Subgrupo D1. Abajo: Subgrupo D2. Camelids of Group D. Above: Subgroup D1. Below: Subgroup D2.

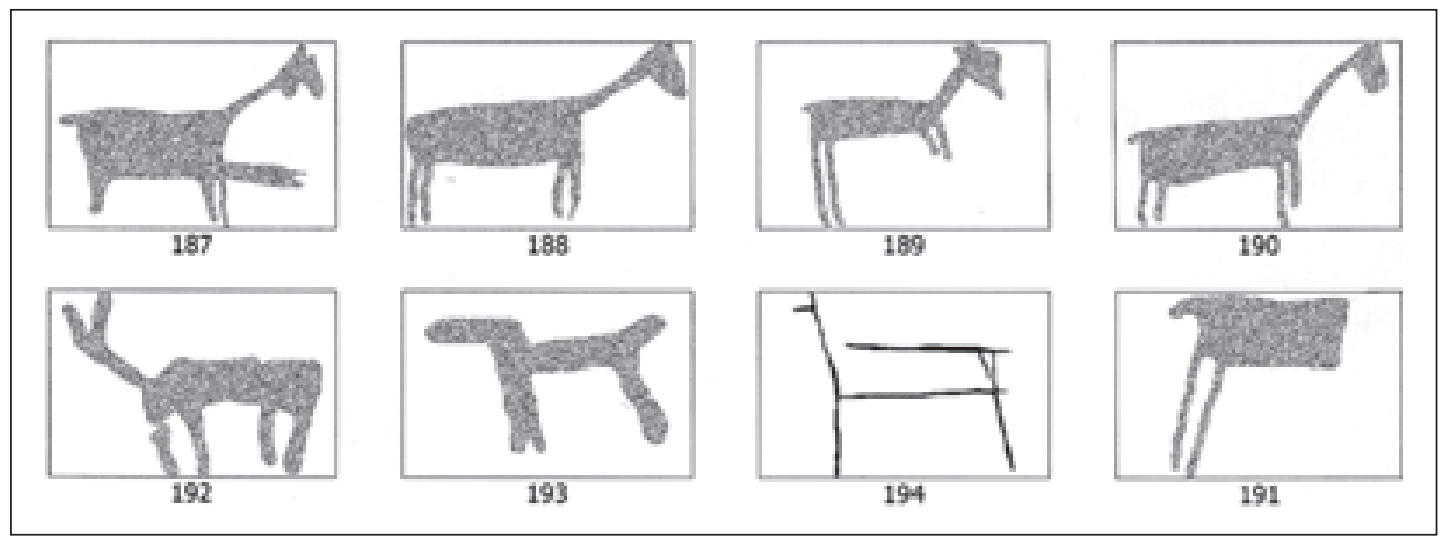

Figura 9. Camélidos del Grupo E.

Camelids of Group E.

po grueso tendiendo a rectangular, cola mayoritariamente recta hacia atrás y minoritariamente doblada hacia abajo, extremidades verticales y oblicuas y sin patas (Figura 9).

\section{Dinámica intraestilística}

Para explorar la dinámica interna del Estilo Santa Bárbara I en SBa-518, en esta parte del artículo analizamos los grupos A, B, C, D y E en términos de dos hipótesis de cambio en la figuración del camélido que son mutuamente excluyentes. Podría haber más, pero en este estudio nos concentramos en estas dos, ya que su oposición neta permite discutirlas como "hipótesis rivales".

Hipótesis 1. Dado que B, C, D y E representan sólo el $19 \%$ de la muestra de esquemáticos, se propone que estos grupos son diferentes experimentaciones con la figuración del camélido rectilíneo, como resultado de las cuales se arriba a una síntesis que es el Grupo A. En el marco de esta hipótesis es factible discernir las siguientes trayectorias de cambio hacia la uniformidad estilística: en B, C, D2 y E los camélidos presentan cuatro extremidades, en cambio en A y D1, exhiben sólo dos. En consecuencia, existe una clara tendencia en estos últimos a reducir a la mitad el número de extremidades representadas. Este proceso se nota a lo largo de las trayectorias $\mathrm{B} \rightarrow \mathrm{E} \rightarrow \mathrm{A}$, $\mathrm{C} \rightarrow \mathrm{A}$ y D2 $\rightarrow \mathrm{D} 1 \rightarrow \mathrm{A}$. Otro proceso de cambio es el perfilamiento que experimenta la figura del camélido respecto de la variedad representacional mostrada en C, D2 y E. Dicho proceso se advierte a lo largo de la trayectoria $\mathrm{E} \rightarrow \mathrm{B} \rightarrow \mathrm{A}$, en que el cuerpo del camélido se torna cada vez más angosto y con una forma más grácil y estandarizada. Esto se observa asi- 
mismo en la trayectoria D2 $\rightarrow$ D1 $\rightarrow$ A, ya que el camélido pierde linealidad y ortogonalidad, dando como resultado final un esquematismo menos acentuado o más realista. Un tercer proceso de cambio es la incorporación de patas en las extremidades del camélido. Esta tendencia de variación ocurre a lo largo de las trayectorias $\mathrm{B} \rightarrow \mathrm{A}$ y $\mathrm{C} \rightarrow \mathrm{A}$. En este último, la pérdida se correlaciona con la virtual desaparición de bulto pectoral y otras protuberancias en el animal.

En este primer escenario hipotético, podrían proponerse tres episodios o "tiempos" (Figura 10). Un $\mathrm{t}_{1}$, en que E, C y D2 mantienen la convención -de larga data en el arte rupestre de la región- de representar las cuatro extremidades del animal, al mismo tiempo que inician un proceso de esquematización respecto del naturalismo de estilos como Taira. Un $\mathrm{t}_{2}$, en que $\mathrm{B}$ conserva las cuatro extremidades, pero incorpora de $\mathrm{C}$ la oreja y cola encorvadas, así como las patas, tendiendo a un mayor perfilamiento de la figura; $y$ en que D1 acentúa el esquematismo y representa tan sólo dos extremidades. Finalmente, un $t_{3}$, en que $\mathrm{A}$ es el grupo resultante de todos los ensayos previos, pero con una mayor identificación formal con $\mathrm{C}$.

Hipótesis 2. Dado que el Grupo A constituye el $81 \%$ de la muestra de esquemáticos, se propone la hipótesis opuesta, esto es, que este grupo de camélidos rectilíneos es el modelo o paradigma estilístico a partir del cual el resto de los grupos introdujeron variaciones. Dentro de esta hipótesis es posible discernir las siguientes trayectorias de cambio hacia la diversidad estilística: con la excepción de A y D1, cuyos camélidos presentan solamente dos extremidades, B, C, D2 y E muestran cuatro

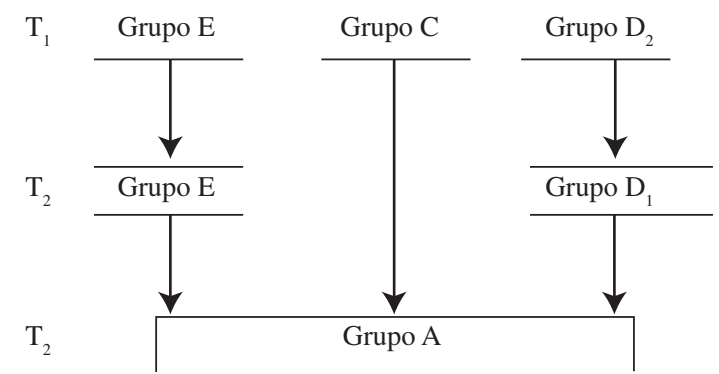

Figura 10. Dendrograma de los grupos esquemáticos, según el Escenario 1.

Dendogram of schematic groups, according to Scenario 1. extremidades. Hay por lo tanto una definida tendencia en estos últimos a doblar el número de este atributo. Este proceso se nota a lo largo de la trayectoria $\mathrm{A} \rightarrow \mathrm{B} \rightarrow \mathrm{E}, \mathrm{A} \rightarrow \mathrm{C}$ y de la trayectoria $\mathrm{A} \rightarrow \mathrm{D} 1 \rightarrow \mathrm{D} 2$. Otro proceso de cambio es el desperfilamiento de la figura del camélido respecto del estándar representado por A. Este proceso es observable a lo largo de la trayectoria $\mathrm{A} \rightarrow \mathrm{B} \rightarrow \mathrm{E}$, en que el cuerpo del camélido se torna cada vez más ancho y con una forma más grosera o chapucera. También se observa en la trayectoria $\mathrm{A} \rightarrow \mathrm{D} 1 \rightarrow \mathrm{D} 2$, ya que el camélido se vuelve hiperrectilíneo y con una fuerte tendencia a la ortogonalidad, dando como resultado final un esquematismo extremo. Un tercer proceso de cambio es la incorporación de patas en las extremidades del camélido. Esta tendencia de variación ocurre a lo largo de las trayectorias $\mathrm{A} \rightarrow \mathrm{B}$ y $\mathrm{A} \rightarrow \mathrm{C}$. En esta última, el cambio parece correlacionarse con la paulatina incorporación de bulto pectoral y otras protuberancias en la imagen del animal, ya insinuada en algunos ejemplares de $\mathrm{A}$.

En este segundo escenario, también podrían proponerse tres episodios o "tiempos" (Figura 11). Un $\mathrm{t}_{1}$, en que existe únicamente $\mathrm{A}$, que sería el grupo de origen del conjunto, si bien carente de toda vinculación con el Estilo Taira u otro de la región. Un $\mathrm{t}_{2}$, en que $\mathrm{B}$ comienza una tendencia al desperfilamiento formal y $\mathrm{C}$ emprende una tendencia a la ortogonalidad, apareciendo en ambos casos cuatro extremidades; y en que D1 empieza una tendencia a la linealidad, pero conservando las dos extremidades y orejas encorvadas de A. Finalmente, un $t_{3}$, en que $\mathrm{E}$ completa el proceso de desperfilamiento notado en B; y en que D2, concluye el proceso de

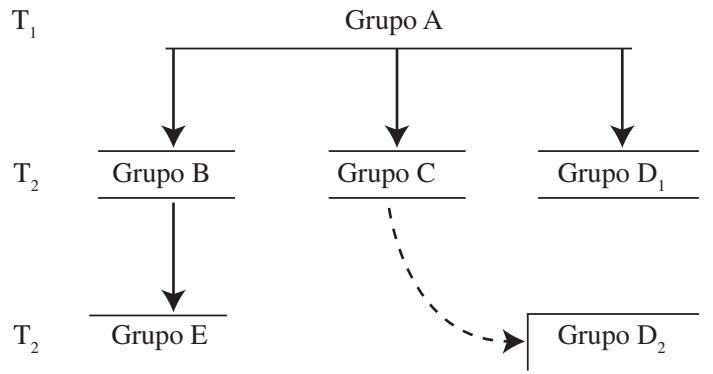

Figura 11. Dendrograma de los grupos esquemáticos según el Escenario 2.

Dendogram of schematic groups, according to Scenario 2. 


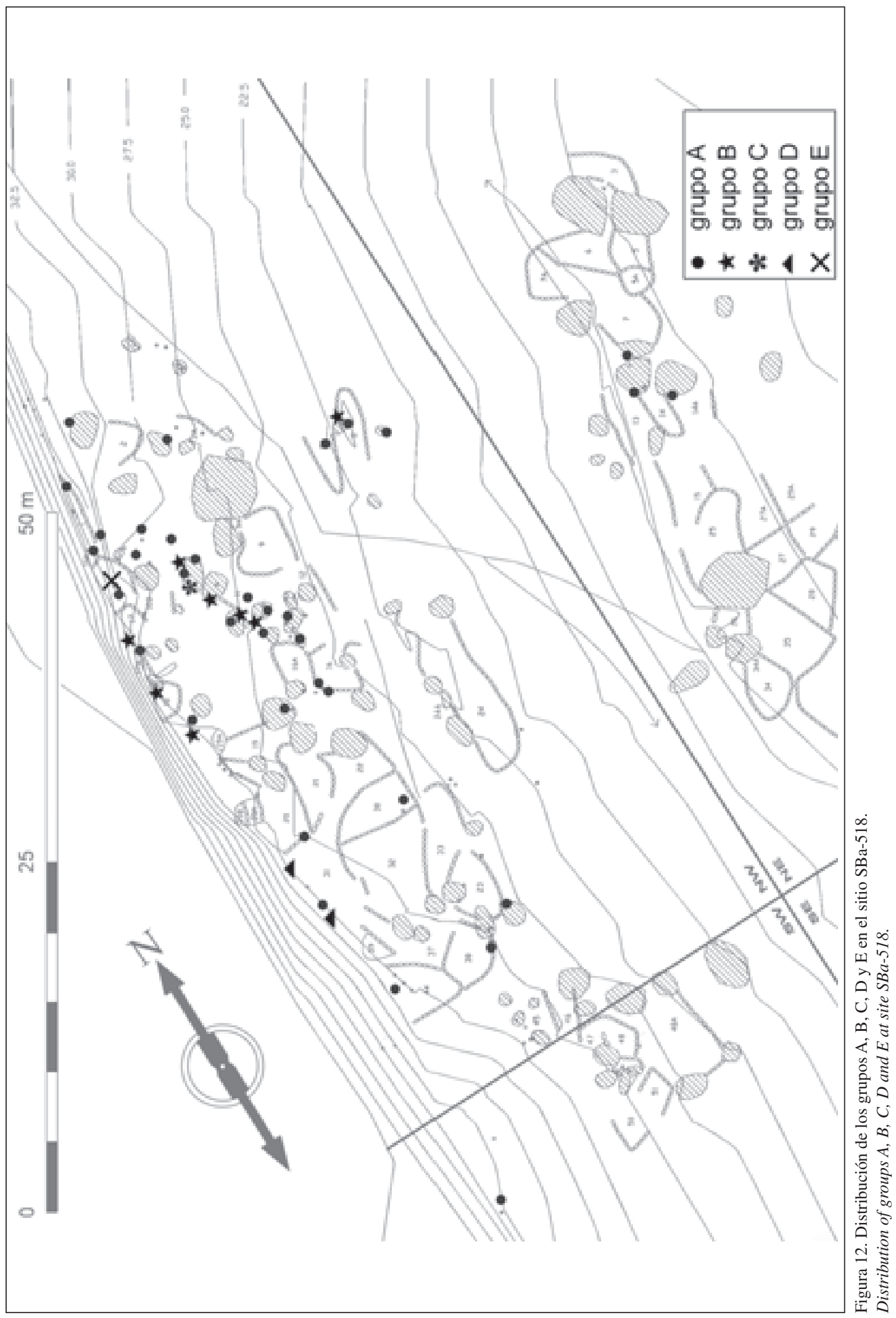


linealidad advertido en D1, recibiendo probablemente influencias de $\mathrm{C}$, como se aprecia por la incorporación de cuatro extremidades.

En suma, el supuesto en nuestra Hipótesis 1 ha sido que la tendencia general de cambio en la figuración del camélido se desarrolló en una secuencia de tres "tiempos", desde la diversidad a la uniformidad. En la Hipótesis 2, el supuesto ha sido que dicha tendencia se desarrolló igualmente en tres "tiempos", pero que tuvo lugar en sentido contrario, esto es desde la uniformidad a la diversidad. A continuación discutimos estas "hipótesis rivales" con datos independientes, para sopesar la validez de cada una de las secuencias resultantes.

\section{Discusión}

Una observación que salta de inmediato a la vista cuando se recorre el sitio, es que la distribución de los paneles esquemáticos guarda una estrecha relación con la arquitectura actualmente visible en SBa-518. Esto es especialmente válido para los camélidos esquemáticos de Referente 2. Dada la historia ocupacional del sitio, hay, entonces, fundamentos espaciales para suponer que estas imágenes conforman el grueso del arte rupestre contemporáneo con el período de actividad del asentamiento. La segregación de grupos al interior de este conjunto estilístico permite ahora llevar esta observación a un nivel más detallado (Figura 12), emergiendo patrones sobre el comportamiento espacial de tales grupos en el sitio.

La revisión de la distribución del Grupo A muestra que, de sus 35 paneles, 31 se hallan en el cuadrante NW, en el sector alto del sitio (E-1, -8, -8A, $10,-10 \mathrm{~A},-11,-12,-16,-17 \mathrm{~A},-18,-30,-31,-38$ y -44), que es el área de mayor densidad de recintos. Otros tres paneles se encuentran en el cuadrante NE, en el sector bajo del asentamiento (E-7 y -14); existe tan sólo uno en el cuadrante SW, sector alto, pero sin asociación a estructuras; y ninguno en el cuadrante SE. Mucho más restringida es la distribución de los otros cuatro grupos. El plano de distribución muestra que los nueve paneles del Grupo B están en el cuadrante NW, todos en el extremo norte del sector alto del sitio (E-8, -11, -12, -17A y -18). El único panel del Grupo C, en tanto, también está en ese cuadrante y en el extremo norte del sector alto, aunque sin asociación a una estructura en particular; sin embargo, se halla en centro del "patio". Los dos paneles del Grupo D, por su parte, se hallan igualmente en el cuadrante NW y en el sector alto, pero algo desplazados hacia el sur, específicamente en el interior de E-31. Finalmente, el único panel del Grupo E comparte con los anteriores el mismo cuadrante, situándose en el extremo norte del sector alto del sitio, dentro de E-10. Es decir, todos los grupos están en el núcleo del asentamiento, pero sólo A se extiende hacia el sector bajo. Con estos patrones espaciales, ciertas consideraciones estilístico-iconográficas y la historia ocupacional del sitio, ahora es factible discutir los dos escenarios hipotetizados en términos de sus principales fortalezas y debilidades.

\section{Escenario 1}

Este escenario propone un inicio en $\mathrm{t}_{1}$, conformado por $\mathrm{E}, \mathrm{C}$ y D2; seguido por un $\mathrm{t}_{2}$, representado por B y D1; y culminando en un $\mathrm{t}_{3}$, en que $\mathrm{A}$ es el grupo resultante de las experimentaciones previas.

\section{Fortalezas de este escenario}

(1) Por una parte, en el Alto Loa hemos observado que los llamados sitios de "conglomerados habitacionales de talud" se originan en torno a abrigos rocosos de la pared del cañón y que, a medida que crecen en cantidad de recintos a lo largo del tiempo, se extienden hacia abajo por el declive (Berenguer et al. 2004b:247, 496). En el Sector Santa Bárbara, este proceso ha sido documentado en dos etapas separadas: caseríos como SBa-153, $-154,-155,-156,-157,-158$ y -159 , de la Fase Laguna (ca. 950-1200 DC), representan la primera etapa de este proceso y caseríos como SBa-103 y -119 , de las fases Quinchamale I (ca. 1.200-1.300 d.C.) y II (ca. 1.300-1.480 d.C.) caracterizan la segunda etapa. El desarrollo de SBa-518 como asentamiento podría calzar perfectamente con este proceso, sólo que ambas etapas habrían ocurrido en el mismo sitio. De ahí que sea consistente con este proceso de desarrollo un tiempo temprano para los escasos paneles de B, C, D y E, concentrados en el sector alto del sitio, ya que estos grupos reflejarían la actividad rupestre de los comienzos del asentamiento. En este contexto, la amplia distribución del Grupo A y su gran cantidad, reflejarían la etapa final en el crecimiento del caserío. En otras palabras, el área cubierta por el arte rupestre esquemático iría aumentando en correspondencia con 
el incremento del área abarcada por las construcciones arquitectónicas.

(2) Otra fortaleza de este escenario se basa en consideraciones estilístico-iconográficas. La representación de camélidos de cuatro extremidades está en la mejor tradición de arte rupestre del período Formativo local, particularmente del Estilo Taira (Berenguer 1995), cuya presencia es cuantitativamente importante en SBa-518. En este sentido, B, C, D1 y E podrían ser los grupos más tempranos, en la medida en que recogerían ese atributo de la vieja tradición y luego lo perderían, primero con D2 y finalmente con A.

(3) En el Sector Santa Bárbara, imágenes de camélidos de los grupos C y D2 aparecen en el techo de un alero rocoso del caserío SBa-153. Están grabadas sobre el hollín dejado por un fogón fechado en 990 d.C., el que, a su vez, cubre motivos de Estilo Taira (Berenguer 1999:36, 2004b:436437, Figuras 9.8c, 9.17a). Sin ser concluyente, esta evidencia apoya nuestro primer escenario, en la medida que sugiere que tales grupos son tempranos dentro de la secuencia.

\section{Debilidades de este escenario}

(1) La fortaleza 2 insinúa un origen autóctono para los "camélidos esquemáticos", lo que es muy improbable, ya que éstos -con diferentes tratamientos estilísticos, por cierto- tienen una vasta distribución en los Andes Centro-Sur y es difícil que SBa-518 o el Alto Loa constituyan su punto de irradiación.

(2) Las implicaciones de la fortaleza 3 para la ubicación del Grupo A como cierre de la secuencia deben ser relativizadas, porque en el mismo panel del citado alero de SBa-153 hay también camélidos de este último grupo (véase Berenguer 1999:36, centro izquierda de la fotografía).

(3) La representación de patas en las extremidades de los camélidos del Grupo $\mathrm{C}$ es un rasgo ajeno a la tradición de arte rupestre local y más propia de la figuración de camélidos en otros sistemas gráficos de data tardía (p.ej. cerámica, figurillas de metal), de manera que este grupo difícilmente podría ser ubicado en los inicios de la secuencia.

(4) El Grupo C presenta un caso de camélido "montado" por un antropomorfo (Figura 7, motivo 031). Como los camélidos no son animales de monta, este caso puede estar reflejando contactos con jinetes europeos, lo que instalaría a este grupo al final de la secuencia y no al principio.

(5) En el sitio Quebrada de Tambores-2, al noroeste de San Pedro de Atacama, camélidos de cuatro extremidades -incluso uno con figuración de patas-comparten un panel con dos representaciones de tianas (Núñez et al. 1997: Figura 7). Dado que estas banquetas eran emblemas de autoridad entre los incas (Martínez 1995), tales atributos en los animales adyacentes deberían considerarse tardíos y no tempranos dentro de la secuencia propuesta.

\section{Escenario 2}

Este escenario propone un comienzo en $\mathrm{t}_{1}$, representado únicamente por $\mathrm{A}$, que sería el grupo de origen del conjunto; sucedido por un $t_{2}$, integrado por B, C y D1; y concluyendo en un $\mathrm{t}_{3}$, conformado por $\mathrm{E} y \mathrm{D} 2$.

\section{Fortalezas de este escenario}

(1) El Grupo A, como inicio de la secuencia, supone un fuerte quiebre estilístico respecto del naturalismo que prevalece en la previa tradición rupestre local (estilos Taira y La Isla), sugiriendo un origen alóctono que es consistente con la amplia distribución de los "camélidos esquemáticos" en los Andes Centro-Sur.

(2) La altísima frecuencia del Grupo A es congruente con la gran cantidad y profundidad cronológica de los fragmentos cerámicos del período Intermedio Tardío, así como con una arquitectura casi totalmente local. En tanto que la bajísima frecuencia de los grupos B, C, D y E es congruente con la escasísima cantidad de fragmentos cerámicos y rasgos arquitectónicos del Horizonte Tardío y Postcontacto en el sitio. Estos datos apoyan que A es un arte rupestre que precede al de los otros grupos en la secuencia del sitio.

(3) La incorporación de patas en las extremidades de los camélidos del Grupo $\mathrm{C}$ es un rasgo propio de la figuración del camélido por parte de otros sistemas gráficos de data tardía (p.ej., cerámica, figurillas de metal), hecho que tiende a confirmar una ubicación más reciente para este grupo en la secuencia.

(4) Camélidos del Grupo E aparecen superpuestos a personajes con unkus y motivos "escutiformes" en el alero SBa-110, en el Sector Santa 
Bárbara (Berenguer 1999:47). Como estas últimas pictografías son tardías dentro del arte rupestre de ese sector del Alto Loa (Berenguer 2004b:444445), habría que concluir que E es más tardío aún, confirmando la ubicación de este grupo al final de la secuencia.

\section{Debilidades de este escenario}

(1) La gran cantidad y dispersión del Grupo A en el sitio tiende a presentarlo como un arte rupestre más bien de finales de la secuencia, esto es, cuando el asentamiento ha alcanzado su mayor extensión y complejidad ocupacional.

(2) Se sabe de al menos un caso de camélido, asimilable a nuestro Grupo A, que se halla montado por un antropomorfo con sombrero (ala y copa) en el sitio SBa-141, en el Sector Santa Bárbara (véase Berenguer 1999:47, abajo izquierda). Como los camélidos no son animales de monta y ese tipo de tocado únicamente arriba a la región con los europeos, el Grupo A debería situarse al final de la secuencia.

Comparando ambos escenarios, se convendrá en que la balanza se inclina a favor del Escenario 2. Éste presenta mucho más fortalezas y menos debilidades que el Escenario $1 \mathrm{y}$ parece claro que el sentido del cambio en la figuración de los camélidos esquemáticos está mejor representado por el segundo escenario. Sin embargo, el peso de la fortaleza 1 del primer escenario y su correspondiente reflejo en el peso que tiene la debilidad 1 del segundo, son difíciles de soslayar teniendo en cuenta la historia ocupacional y constructiva del sitio. Topamos aquí con un problema difícil de resolver dentro del marco exclusivo de estas dos hipótesis.

\section{Un tercer escenario}

La solución de este dilema pasa, a nuestro juicio, por considerar un tercer escenario, muy similar al segundo, pero que se hace cargo de su principal debilidad. Este Escenario 3 propone un comienzo en $\mathrm{t}_{1}$, representado únicamente por $\mathrm{A}$, que sería el grupo de origen del conjunto; sucedido por un $t_{2}$, representado por D1; seguido a su vez por un $t_{3}$, integrado no sólo por B, C y D2, sino también por un $\mathrm{A}^{\prime}$; y concluyendo en un $\mathrm{t}_{4}$, conformado por $\mathrm{E}$ ( $\mathrm{Fi}$ gura 13). La trayectoria $\mathrm{A} \rightarrow \mathrm{A}^{\prime}$ reflejaría la persistencia de este grupo durante $t_{1}, t_{2} \mathrm{yt}_{3}$. Esta secuencia explicaría por qué $\mathrm{A}$, siendo el grupo "alfa", se halla presente tanto en las estructuras más tempranas como en las más tardías (Debilidad 1 del Escenario 2). Señala también, que en los comienzos de la historia ocupacional del sitio el área de distribución del arte rupestre esquemático era mucho más grande que la de las construcciones, y que sólo al final de la secuencia ambos aspectos tienden a equipararse. Además, el nuevo escenario posee capacidad heurística. Por ejemplo, contribuye a explicar por qué algunos camélidos del Grupo A tienen tres extremidades en lugar de dos y por qué otros exhiben bulto pectoral o patas en las extremidades, todos atributos iconográficos evaluados como tardíos. Responderían quizás a "influencias" horizontales provenientes de sus grupos coetáneos. También da cuenta de la debilidad 2 del segundo escenario, ya que si A se prolonga hasta $\mathrm{t}_{3}$ a través de A', se puede entender que algunos camélidos de este grupo aparezcan montados en SBa-141. Otro valor de este escenario es que ubica a $\mathrm{E}$ como el grupo más tardío de la secuencia, sugiriendo que la actividad rupestre continúa en el sitio en tiempos Postcontacto.

\section{Conclusiones}

Hernández Llosas (1991:61) sostuvo hace casi 15 años que la identificación de "lo inca" en el arte rupestre es un objetivo importante y buscado por los investigadores del tema, pero que no se han detectado motivos que puedan adscribirse al "momento inca" en ninguna parte de los Andes, incluyendo el Cuzco (véase también Podestá 1986-87:257). Aunque en la actualidad la primera autora probablemente no se siente interpretada en su totalidad por este planteamiento (véase Hernández Llosas 2006), creemos que el objetivo sigue vigente y la falta de evidencia

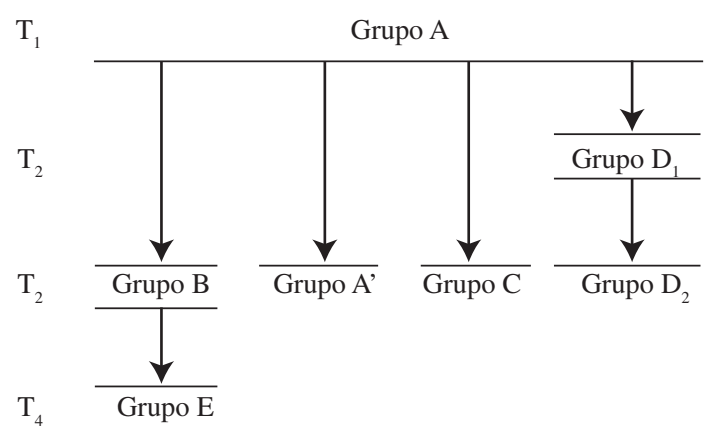

Figura 13. Dendrograma de los grupos esquemáticos, según el Escenario 3.

Dendogram of schematic groups, according to Scenario 3. 
continúa siendo en gran parte válida hasta hoy. La dificultad en alcanzar esta meta es evidente en este propio artículo. Cuando se intenta fechar el arte rupestre mediante el género de procedimientos indirectos utilizado por nosotros, es preciso considerar una variedad de líneas de evidencia. En lo esencial, nuestro procedimiento ha sido una indagación estilístico-iconográfica, pero complementada con diversos datos propiamente arqueológicos. Por desgracia, el resultado de este tipo de análisis nunca es totalmente concluyente, cuestión que torna incierto cualquier empeño por adjudicar un estilo a un desarrollo cultural concreto. Por añadidura, el período incaico es tan corto (poco más de 100 años en nuestra región), que aunque se emplearan métodos de datación directa, difícilmente proporcionarían fechas con la resolución cronológica requerida. Pero el hecho de que algo sea difícil de investigar y que el resultado sea por lo común ambiguo, no significa que no haya que intentarlo. Y nosotros lo hemos intentado aquí sobre la base de una cuidadosa y ponderada interrelación de datos y suma de argumentos, planteando hipótesis y sopesando la validez de escenarios diferentes y contrastados. Reiteremos en todo caso, a modo de prevención, que nuestras conclusiones se basan exclusivamente en los diseños de Referente 2, que constituyen sólo el $60 \%$ del universo del sitio.

Quizás, el punto que ha entrampado a muchos investigadores es que han focalizado su búsqueda en identificar un arte rupestre figurativo estrictamente incaico, cuando es probable que nunca haya existido tal cosa. Nosotros nos hemos aproximado al problema desde una perspectiva diferente. Hemos partido de la presunción fundada de que los camélidos esquemáticos se originaron en diferentes partes de los Andes Centro-Sur mucho antes de los incas (Berenguer 2004b:436-444) y en este trabajo hemos llegado a una cierta convicción de que, al menos en el sitio SBa-518, conservaron su vigencia durante el Tawantinsuyu. La prolongación hasta el Horizonte Tardío de cerámicas locales propias del período previo en muchas partes de los Andes Centro-Sur, proporciona un buen modelo para esta posibilidad (Berenguer y Cabello 2005).

La segregación de grupos al interior del Estilo Santa Bárbara I y la exploración de su dinámica intraestilística a lo largo del tiempo en SBa-518, nos permitió hipotetizar trayectorias de cambio en la figuración del camélido, ensayar distintas secuencias de estos grupos y evaluar su congruencia con la historia ocupacional del sitio. Pese a que en una primera instancia la evaluación tendió a favorecer nuestro Escenario 2, una más cuidadosa ponderación de los datos arqueológicos locales instaló al final del análisis un Escenario 3, no previsto por nuestro diseño de prueba original. Este nuevo escenario también propone que A es el grupo "alfa", a partir del cual se originan los otros grupos presentes en el sitio, pero propone, además, que A no se extingue a medio camino de este proceso, sino que se mantiene vigente desde el Intermedio Tardío hasta bien entrado el Horizonte Tardío (A'). Es esta reflexión la que posibilita, a nuestro modo de ver, identificar a los grupos A' y C, y al subgrupo D2, como los que, con mayor probabilidad, pueden atribuirse al Horizonte Tardío en SBa-518. Sin embargo, queremos ser muy claros en precisar lo siguiente: no creemos que se trate de actividad rupestre propiamente incaica o "emblemática" del Inca, ni siquiera de arte rupestre "inca local" o "inca provincial”, para seguir con las analogías cerámicas. Quienes se inclinen por esta posibilidad, deberán explicar primero por qué no hay arte rupestre en el vecino sitio CG-9 o en sus alrededores. Y, en segundo lugar, por qué tampoco lo hay en el camino inca y en ningún otro asentamiento incaico del valle. En nuestra opinión, se trata, más bien, de subestilos locales que serían parcial (en el caso de A) o totalmente (en los casos de C y D2) contemporáneos con el Tawantinsuyu en la región.

Digamos para finalizar que, conforme a nuestra apreciación global del sitio, SBa-518 fue un asentamiento agropastoril de intensa ocupación y profunda raigambre en el período Intermedio Tardío, pero que, poco antes o poco después de construirse el camino inca, pasó a convertirse en un asentamiento-satélite de CG-9. Esto es, en un sitio al servicio de esa instalación incaica, donde seguramente se producían, preparaban, consumían y almacenaban alimentos para los agentes y funcionarios estatales que hacían la ruta del Alto Loa. Seguramente a estas relaciones de servidumbre se deben las "anomalías" de SBa-518 cuando se le coteja con otros caseríos cercanos. Por ejemplo, su cantidad de recintos, demasiado alta para los estándares locales; la modificación de la estructura social y demográfica del asentamiento original, que pasó de un pequeño caserío unifamiliar a un villorrio plurifamiliar; la insólita abundancia de instrumentos de molienda; la gran cantidad de basuras; el "patio", un espacio comunal no visto antes en los caseríos del valle; y tal 
vez, la construcción de un par de recintos con mampostería más elaborada que la usual en el área.

Pese al impacto producido por los incas en las cercanías y a la reorganización que por este motivo debe haber experimentado el propio asentamiento SBa-518, pensamos que los habitantes de este sitio siguieron produciendo arte rupestre esquemático durante el Horizonte Tardío, como lo habían venido haciendo sus antepasados desde mucho antes y, como, aparentemente, continuaron haciéndolo sus sucesores después del contacto con los españoles.

Dicho esto, no quisiéramos dejar la impresión de que descartamos de plano la existencia en el norte de Chile de un arte rupestre exclusivo del Horizonte Tardío. Es muy posible que ciertos diseños geométricos y horadaciones analizados por Valenzuela et al. (2004; véase también Gallardo et al. 1999 y Hernández Llosas 2006) merezcan esa connotación. De hecho, en nuestro artículo hemos dejado fuera de análisis las cúpulas ovales o rectangulares del sitio SBa-518, que podrían caer perfectamente en esas categorías. Sin embargo, el tema central en nuestro artículo han sido los camélidos esquemáticos, particularmente los de la II Región de Chile. Aclaremos finalmente que entendemos que nuestro caso de estudio no es (ni tendría porqué ser) un caso único en los Andes, pero será tarea de otros investigadores revisar sus datos y evaluar si nuestra evaluación de la situación en SBa-518 es la misma, es parecida o es distinta en sus respectivas áreas de trabajo.

Agradecimientos: La investigación para este artículo fue financiada por el proyecto FONDECYT 1010327, "Arqueología del sistema vial de los inkas en el Alto Loa, II Región de Chile". Agradecemos la colaboración de Francisco Gallardo en la elaboración de un análisis de cluster que contribuyó a clarificar nuestros primeros agrupamientos de subestilos, como también a José Blanco, Soledad Donoso, Magdalena García, Jimena Torres y Álvaro Reyes por su ayuda en el registro de los paneles, y a Constanza Aliaga por el levantamiento de las figuras. Vaya también un reconocimiento para los evaluadores externos por sus valiosos comentarios.

\section{Referencias Citadas}

Aschero, C.

1979 Aportes al estudio del arte rupestre de Inca Cueva-1 (Departamento de Humahuaca, Jujuy). Actas de las Jornadas de Arqueología del Noroeste Argentino. Antiquitas 2:419-459.

Berenguer, J.

$1995 \mathrm{El}$ arte rupestre de Taira dentro de los problemas de la arqueología atacameña. Chungara 27:7-43.

1999 El evanescente lenguaje del arte rupestre en los Andes atacameños. En Arte Rupestre en los Andes de Capricornio, editado por J. Berenguer y F. Gallardo, pp. 9-56. Museo Chileno de Arte Precolombino, Banco Santiago, Santiago.

2004a Cinco milenios de arte rupestre en los Andes atacameños: imágenes para lo humano, imágenes para lo divino. Boletín del Museo Chileno de Arte Precolombino 9:75-108. 2004b Caravanas, Interacción y Cambio en el Desierto de Atacama. Sirawi Ediciones, Santiago.

Berenguer, J. y G. Cabello

2005 Late Horizon rock art in the Atacama Desert? A view from the Inka Road. Rock Art Research 22:83-86.

Berenguer, J., G. Cabello y D. Artigas

2004 Variabilidad, dinámica intraestilística y espacialidad de los camélidos esquemáticos en el arte rupestre de SBa-518. Manuscrito en posesión de los autores.

Berenguer, J.; I. Cáceres, C. Sanhueza y P. Hernández

2005 El Qhapaqñan en el Alto Loa, norte de Chile: un estudio micro y macromorfológico. Estudios Atacameños 29:7-39.

Gallardo, F., C. Sinclaire y C. Silva

1999 Arte rupestre, emplazamiento y paisaje en la cordillera del desierto de Atacama. En Arte Rupestre en los Andes de
Capricornio, editado por J. Berenguer y F. Gallardo, pp. 57-96. Museo Chileno de Arte Precolombino, Banco Santiago, Santiago.

Gallardo, F. y F. Vilches

1995 Nota acerca de los estilos de arte rupestre en el Pukara de Turi (Norte de Chile). Boletín de la Sociedad Chilena de Arqueología 20:26-28.

Hernández Llosas, M.I.

1991 Modelo procesual acerca del sistema cultural Humahuaca Tardío y sus modificaciones ante el impacto invasor europeo: implicaciones sobre las representaciones rupestres. En El Arte Rupestre en la Arqueología Contemporánea, editado por M.M. Podestá, M.I. Hernández Llosas y S.F. Renard de Coquet, pp. 53-65. Buenos Aires.

2006 Inkas y españoles a la conquista simbólica del territorio Humahuaca: sitios, motivos rupestres y apropiación cultural del paisaje. Boletín del Museo Chileno de Arte Precolombino 11:9-34.

Hyslop, J.

1976 Ichucollo petroglyph (Peru). Bolletino del Centro Camuno di Studi Prehistorici 13-14:214-216.

1984 The Inka Road System. Academic Press, Orlando.

1990 Inka Settlement Planning. University of Texas Press, Austin.

1991 Observations about research on prehistoric roads in South America. En Ancient Road Networks and Settlement Hierarchies in the New World, editado por C.D. Trombold, pp. 28-33. Cambridge University Press, Cambridge.

Hyslop, J., B. Guerrero y L.E. Lumbreras

1992 El camino inka entre el río Yanahuanca (Chaupi Waran- 
ga) y la ciudad Inka de Huánuco Pampa, Departamentos de Pasco y Huánuco, Perú. Gaceta Arqueológica Andina VI (21):55-79.

Martínez, J.L.

1995 Autoridades en los Andes, los Atributos del Señor. Pontificia Universidad Católica del Perú, Fondo Editorial, Lima.

Nielsen, A.

1997 Inkas en Lípez: Primera aproximación. Ponencia presentada en XII Congreso Nacional de Arqueología Argentina, La Plata.

Niemeyer, H. y M. Rivera

1983 El camino del inca en el despoblado de Atacama. Boletín de Prehistoria de Chile 9:91-193.

Núñez, L.

1985 Petroglifos y tráfico de caravanas en el desierto chileno. En Estudios en Arte Rupestre, editado por C. Aldunate, J. Berenguer y V. Castro, pp. 243-264. Museo Chileno de Arte Precolombino, Santiago.

1999 Valoración minero-metalúrgica circumpuneña: menas y mineros para el Inka rey. Estudios Atacameños 18:177-221.

Núñez, L.; I. Cartajena, J.P. Loo, S. Ramos, T. Cruz y H. Ramírez

1997 Registro e investigación del arte rupestre en la Cuenca de Atacama (Informe Preliminar). Estudios Atacameños 14:307-325.

Podestá, M.M.

1986-87 Arte rupestre en asentamientos de cazadores-recolectores y agroalfareros en la puna sur argentina: Antofagasta de la Sierra, Catamarca. Relaciones de la Sociedad Argentina de Antropología 17:241-263.

Sepúlveda, M.

2004 Esquemas visuales y emplazamiento de las representaciones rupestres de camélidos del Loa Superior en tiempos incaicos. ¿Una nueva estrategia de incorporación de este territorio al Tawantinsuyu? Chungara Revista de Antropología Chilena 36:439-451.

Uribe, M. y G. Cabello

2004 ¿Diaguitas en el desierto de Atacama?: Circulación de cerámicas y movimientos poblacionales durante el dominio Inka. Ponencia presentada en $X V$ Congreso Nacional de Arqueología Argentina, Río Cuarto.

2005 Cerámica en el camino: implicancias tipológicas y conductuales para la comprensión de la vialidad y la expansión del Tawantinsuyu en el río Loa (Norte Grande de Chile). Revista Española de Antropología Americana 35:75-98.

Uribe, M. y C. Carrasco

1999 Tiestos y piedras talladas de Caspana: la producción alfarera y lítica en el Período Tardío del Loa Superior. Estudios Atacameños 18:55-87.

Valenzuela, D.; C.M. Santoro y A. Romero

2004 Arte rupestre en asentamientos del período Tardío en los valles de Lluta y Azapa, norte de Chile. Chungara Revista de Antropología Chilena 36:421-437.

Varela, V.

1999 El camino del Inca en la cuenca superior del río Loa, desierto de Atacama, norte de Chile. Estudios Atacameños 18:89-105.

Vilches, F. y M. Uribe

1999 Grabados y pinturas del arte rupestre tardío de Caspana. Estudios Atacameños 18:73-87.

Yacobaccio, $\mathrm{H}$.

1979 Arte rupestre y tráfico de caravanas en la puna de Jujuy: Modelo e hipótesis. Actas de las Jornadas de Arqueología del Noroeste Argentino. Antiquitas 2:392-407. 